\title{
Targeting autophagy to overcome drug resistance: further developments
}

\author{
Haocai Chang ${ }^{1,2}$ and Zhengzhi Zou ${ }^{1,2^{*}}$ (])
}

\begin{abstract}
Inhibiting cell survival and inducing cell death are the main approaches of tumor therapy. Autophagy plays an important role on intracellular metabolic homeostasis by eliminating dysfunctional or unnecessary proteins and damaged or aged cellular organelles to recycle their constituent metabolites that enable the maintenance of cell survival and genetic stability and even promotes the drug resistance, which severely limits the efficacy of chemotherapeutic drugs. Currently, targeting autophagy has a seemingly contradictory effect to suppress and promote tumor survival, which makes the effect of targeting autophagy on drug resistance more confusing and fuzzier. In the review, we summarize the regulation of autophagy by emerging ways, the action of targeting autophagy on drug resistance and some of the new therapeutic approaches to treat tumor drug resistance by interfering with autophagy-related pathways. The full-scale understanding of the tumor-associated signaling pathways and physiological functions of autophagy will hopefully open new possibilities for the treatment of tumor drug resistance and the improvement in clinical outcomes.
\end{abstract}

Keywords: Autophagy, Drug resistance, Metabolic stress, p53, MAPK, miRNA, Therapeutic antibody, Histone deacetylase

\section{Introduction}

Autophagy is a process of self-digestion with highly conservative attributes from yeast to mammals during evolution, which allows cells to sequester cytoplasmic components and fuse with lysosomes for degradation to maintain cellular biosynthesis and energy demand during nutrient deprivation or metabolic stress. In the mammalian cells, the three best-characterized pathways of autophagy are chaperone-mediated autophagy, microautophagy and macroautophagy. The degradation process of chaperone-mediated autophagy is selective to erase the cytoplasmic proteins relying on the recognition by the heat shock cognate 70 (HSC70) chaperone with the recognizable peptide sequence motif (KFERQ)

\footnotetext{
*Correspondence: zouzhengzhi@m.scnu.edu.cn

${ }^{2}$ Guangdong Provincial Key Laboratory of Laser Life Science, College

of Biophotonics, South China Normal University, Tianhe District, 55

Zhongshan Avenue West, Guangzhou 510631, China

Full list of author information is available at the end of the article
}

[1]. Microautophagy directly sequesters the degradation of proteins which are translocated into the lumen in the form of lysosomal membrane invaginations [2]. Macroautophagy sequesters the cytoplasmic proteins or organelles by the expanding phagophore, leading to the formation of the double-membrane autophagosomes, which subsequently fuse with lysosomes [3]. Macroautophagy, referred to as autophagy, is closely related to the occurrence and drug resistance of tumor and chosen to be discussed in the review. Extensive studies have revealed that various signaling pathways regulate the phenomenon of autophagy. The PI3K/AKT/mTOR, LKB1/AMPK and Beclin1 complex are the core regulator of signaling pathways on autophagy. However, recent studies also have showed that p53-related pathways, mitogen-activated protein kinase (MAPK)-related pathways, metabolic stress-induced signaling, microRNAtriggered signaling and lncRNA-triggered signaling also participate in autophagy regulation, which make the role of autophagy on therapeutic drugs more unpredictable

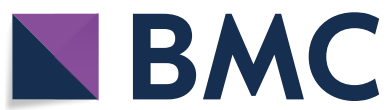

(c) The Author(s) 2020. Open Access This article is licensed under a Creative Commons Attribution 4.0 International License, which permits use, sharing, adaptation, distribution and reproduction in any medium or format, as long as you give appropriate credit to the original author(s) and the source, provide a link to the Creative Commons licence, and indicate if changes were made. The images or other third party material in this article are included in the article's Creative Commons licence, unless indicated otherwise in a credit line to the material. If material is not included in the article's Creative Commons licence and your intended use is not permitted by statutory regulation or exceeds the permitted use, you will need to obtain permission directly from the copyright holder. To view a copy of this licence, visit http://creativecommons.org/licenses/by/4.0/. The Creative Commons Public Domain Dedication waiver (http://creativeco mmons.org/publicdomain/zero/1.0/) applies to the data made available in this article, unless otherwise stated in a credit line to the data. 
because induction of autophagy in response to tumor therapeutics has been considered as a double-edged sword with pro-death and pro-survival functions. Specifically, autophagy can clean up mutated cells, damaged organelles and genomic instability to inhibit tumorigenesis in the early stage of tumor formation $[4,5]$. In established tumors, autophagy can be enhanced as a response to tumor cells against nutrient deprivation, energy deficits, hypoxia stress and chemotherapeutic drugs, finally they gradually induce acquired resistance [5]. Additionally, some tumor cell types with high basal autophagic flux may emerge intrinsic resistance to chemotherapeutic drugs and other targeted therapies. Conversely, persistent or excessive autophagy can induce autophagic cell death in tumor therapy $[6,7]$. There would therefore seem to be a contradiction for the impact of autophagy on tumor. In brief, a further understanding of the mechanisms and functions on autophagy will delineate the multiple roles of autophagy as a novel target for both cancer prevention and cancer therapy.

\section{Mechanisms of autophagy}

Autophagy in mammalian cells has been divided into five stages: induction, vesicle nucleation, vesicle elongation, fusion and degradation (Fig. 1). The initiating signals of autophagy to form the autophagosomes originate from the activated kinase Unc-51-like kinase-1/2 (ULK1/2, human homolog of yeast ATG1) [4, 8], and which then forms a pre-initiation complex with ATG13, ATG17, ATG101 and focal adhesion kinase (FAK) family

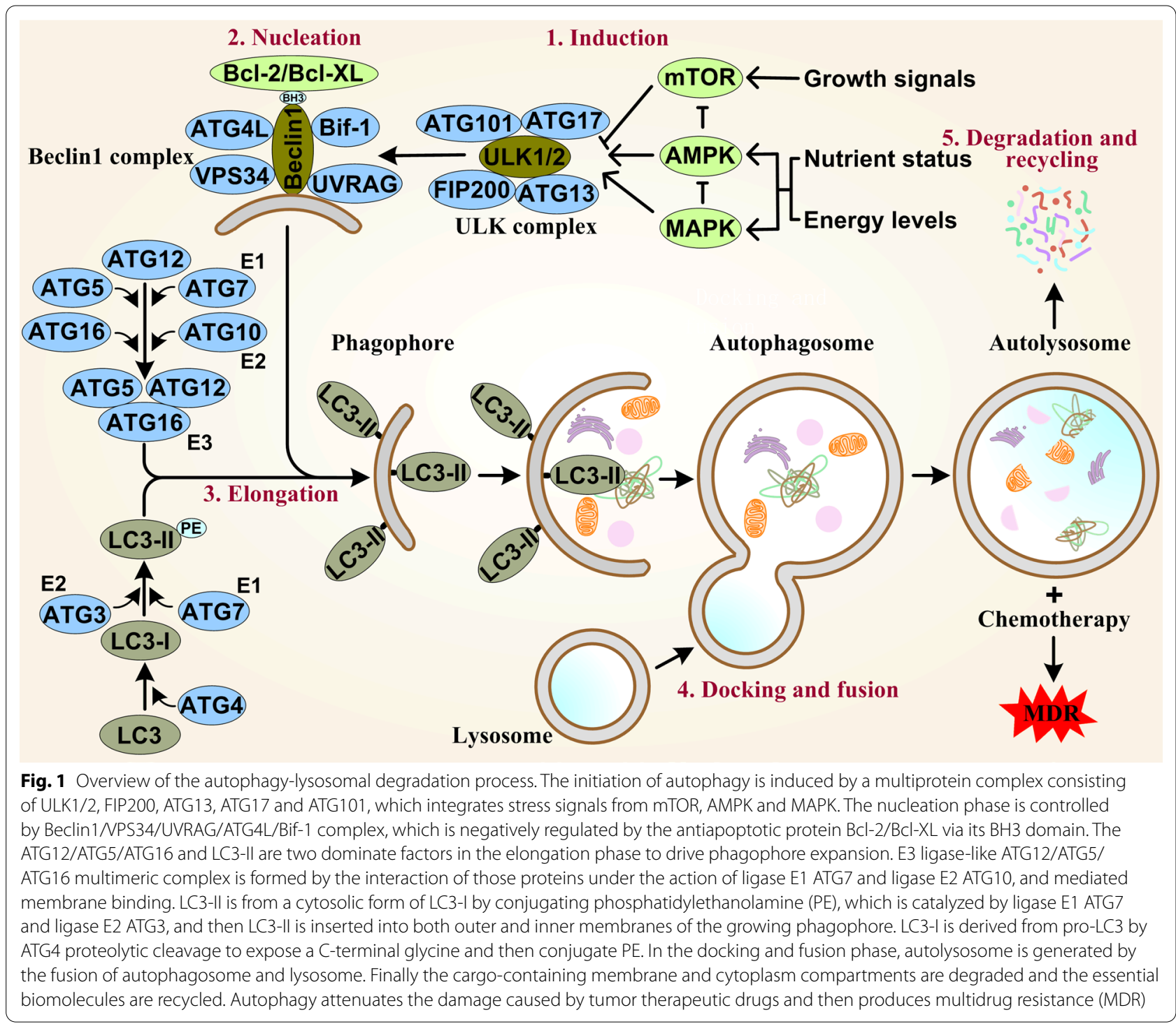


interacting protein 200 (FIP200) under stress conditions [9]. ULK1/2 complex recruits the initiation complex composed of Beclin1 (human homolog of yeast ATG6), ATG14L, type III phosphatidylinositol (PtdIns) 3-kinase PIK3C3/vacuor protein sorting-34 (VPS34), autophagy and Beclin1 regulator-1 (AMBRA-1) and UV radiation resistance-associated gene protein (UVRAG), by phosphorylating Beclin1 to activate the autophagy-specific VPS34 [8]. Beclin1 and ATG14L synergistically facilitate the formation of autophagosomal membrane that is related to ATG5 and ATG12 [10]. Under the catalysis of E1-like enzyme ATG7 and E2-like enzyme ATG10, the formed ATG5/ATG12/ATG16(L) complex facilitates the recruitment and conversion of microtubuleassociated protein light chain 3 (LC3-I) to the membrane-bound LC3-II form [11]. LC3-II also binds to the adaptor protein p62/sequestosome1 (SQSTM1) to degrade the ubiquitinated protein aggregates in autophagolysosome [12], and thus recycling amino acids and other metabolic building blocks to maintain cellular homeostasis.

\section{mTOR and Beclin1-related pathways}

The mammalian target of rapamycin complex 1 (mTORC1) serves as the central modulator of autophagy. Activated mTORC1 inhibits autophagic cascade reaction by phosphorylating ATG13 and ULK1 to block the formation of pre-initiation complex [13], and by phosphorylating ATG14 to suppress the class III PI3K activity of ATG14-containing PIK3C3 [14]. mTORC1 integrates the upstream signaling of class I PI3K/AKT [15] and adenosine monophosphate kinase (AMPK) [16] (Fig. 2), which can sense the nutrient status and energy levels and deliver signaling to the key downstream 4EBP1 and p70S6K, which regulate protein translation. Activated AKT disrupts the accumulation of tuberous sclerosis protein $1 / 2(\mathrm{TSC} 1 / 2)$ heterodimerization to inhibit the GTPase activity of Ras homolog enriched in brain (Rheb), which activates mTORC1 in its GTP-bound form [17]. Upon amino acids deprivation, the translocation of mTORC1 in Rag dependent manner to the lysosomal surface is restrained, which is a necessary event for its activation [18]. At low energy levels, the liver kinase B1 (LKB1, also known as STK11)/AMPK signal axis, as the metabolic sensor, activates TSC1/2 [19], then inactivates mTORC1 activity and ultimately increases autophagy. Also, the inhibition of mTORC1 by AMPK can trigger hypoxia-induced autophagy by hypoxia-inducible factor (HIF)-dependent and independent fashions [20, 21]. In addition, AMPK can also directly phosphorylate and activate ULK1 to organize the pre-initiation complex of autophagy [20, 22].

As an interactome scaffold, Beclin1 can self-associate to induce the formation of autophagosomes via its coiled-coil domain (CCD) $[23,24]$, or interact with antiapoptotic members of the Bcl-2 family to play an opposite role via Bcl-2-homology-3 domain (BH3) [25]. During starvation, the activated c-Jun $\mathrm{N}$-terminal protein kinase 1 (JNK1) phosphorylates Bcl-2 to dissociate it from Beclin1 and activate autophagy [26]. Noteworthy, caspase activated by apoptotic signaling cleaves Beclin1 and PIK3C3 and then yields fragments which lack the capacity to induce autophagy $[27,28]$. The fragments, in turn, enhance the apoptotic signaling to create an amplifying loop of apoptosis [28].

\section{p53-related pathways}

Recent evidence has revealed that p53 plays a bidirectional role in regulating autophagy, which relies on its subcellular localization where nuclear p53 induces autophagy via its transcriptional activity while cytoplasmic p53 represses autophagy via its cytoplasmic functions. In the nucleus, p53 transcriptionally regulates 432 target genes, a host of which are autophagy genes [29]. Upstream of autophagy pathway, $A M P K \beta 1, \beta 2$ and $\gamma$ subunits, PI3K $p 55 \gamma$ subunit, TSC2, phosphatase and tensin homolog $(P T E N)$, DNA-damage-inducible transcript 4 (DDIT4/REDD1) and forkhead box O $3 a$ (FOXO3a) are encoded by p53 target genes to regulate the AMPK and mTOR pathways $[29,30]$. Within core machinery, numerous autophagy genes including $U L K 1 / 2, A T G 2 b$, ATG4a/c, ATG7, ATG10 and UVRAG are all bound by $\mathrm{p} 53$, which are directly involved in or regulate the composition of autophagic complexes [29]. Moreover, several lysosomal protein encoding genes, such as cathepsin $\mathrm{D}$ $(C T S D)$, lysosomal-associated transmembrane protein 4A (LAPTM4A), tripeptidyl peptidase 1 (TPP1) and damage-regulated autophagy modulator $(D R A M)$, are also as p53 target genes which may contribute to the generation of autolysosomes or the degradation of autolysosomal content [29, 31, 32]. Recently, several studies have shown that two other p53-family members, p63 and p73 also transcriptionally regulate the autophagy program. The phosphorylation of $\mathrm{p} 63$ induced by cisplatin transcriptionally upregulates the expression of ULK1, ATG3, ATG5, Beclin1, ATG7 and ATG10 and increases the control of autophagic pathways [33]. The activation of p73 induced by rapamycin starts up the expression of its target genes TSC1, ATG5, PI3K $p 85 \alpha$ subunit and insulin receptor (INSR) to induce autophagy [34,35]. These comparisons among three p53 family members indicate that it's a shared function for them to bind autophagy genes and promote the occurrence of autophagy.

Contrasting with the proautophagic functions of nuclear p53 by transcription-dependent mechanisms, cytoplasmic p53 restrains autophagy under various experimental conditions. Mutant p53 protein with a 


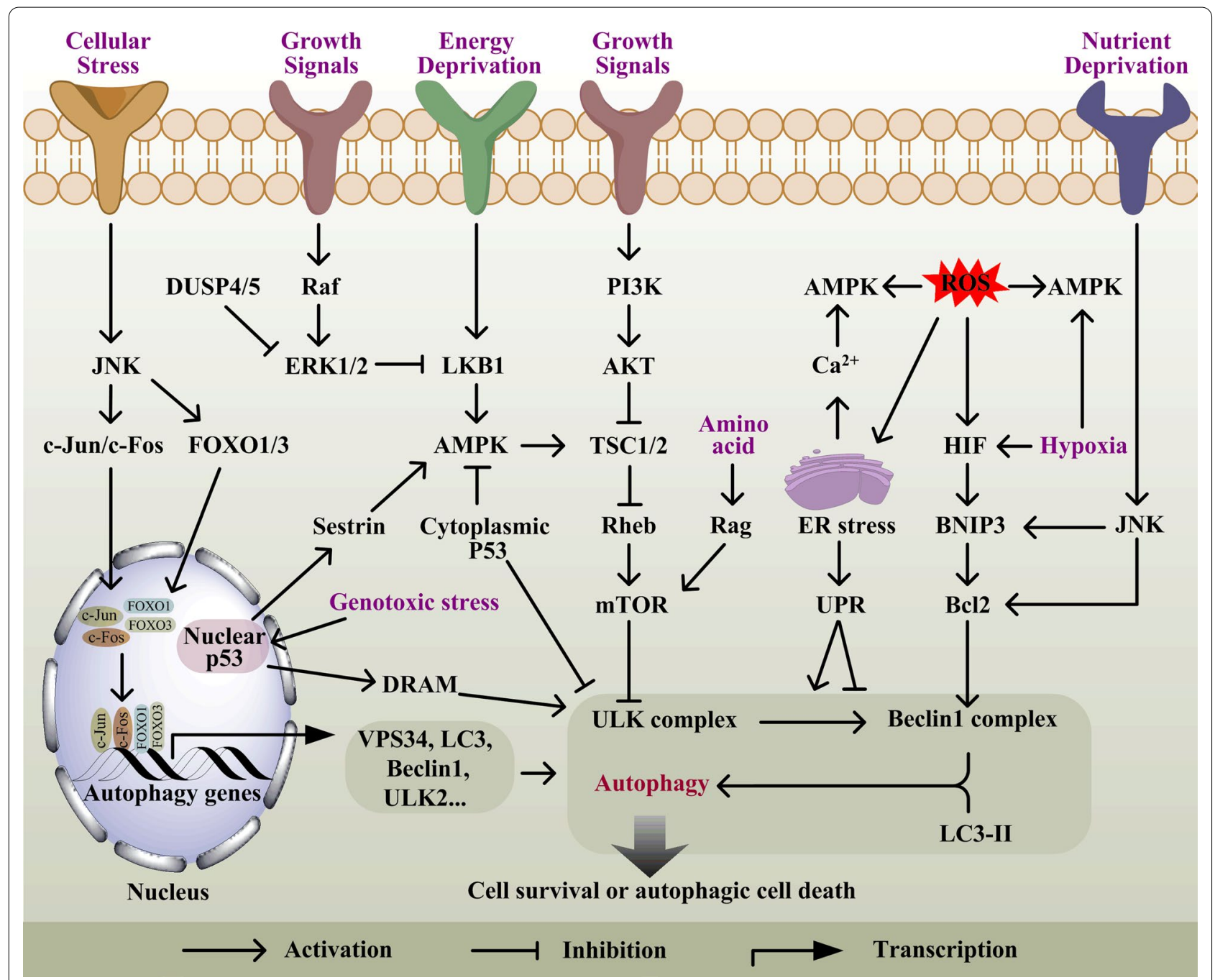

Fig. 2 Regulation of autophagy. Multiple signaling pathways triggered by growth signals and energy status are integrated by mTOR, a core regulator of autophagic signaling, which initiate autophagy induction and inhibition. Cellular stresses, including genotoxic stress, ER stress, hypoxic stress and ROS, also elicit a series of intracellular and extracellular signal events and change the level of autophagic flux through distinct mechanisms

disrupted nuclear localization sequence, resulting in the cytoplasmic retention of p53, can efficiently inhibit autophagy [36]. Furthermore, in enucleated cells, deletion of p53 stimulates autophagy and cytoplasmic, not nuclear, p53 can manifest the capability to abolish the enhanced autophagy in $\mathrm{p} 53^{-/-}$cells. Under pro-apoptotic conditions, p53 rapidly translocates to the mitochondria and triggers mitochondrial membrane permeabilization (MMP) [37], most likely by engaging and repressing the antiapoptotic Bcl-2 family member Bcl-2/Bcl-XL or by activating its proapoptotic counterparts Bax/Bak, which leads to cytochrome $c$ release $[37,38]$. Accompanying p53 mutations on tumor progression, mutant p53 is detained in cytoplasm and loses its transactivation activity and the binding capability with Bcl- 2 family proteins, instead, acquiring the autophagy-inhibitory action [36, 39], which leads to the tumor survival. Although the precise molecular mechanism by which cytoplasmic p53 inhibits autophagy has not been fully investigated, recent studies have showed that mutant p53 inhibits AMPK and activates mTOR, resulting in the suppression of autophagy [40, 41]. Moreover, mutant p53 can stimulate the stability of HIF-1, as an anti-autophagic protein, via intracellular reactive oxygen species (ROS)-mediated pathway [42]. Notably, mutant p53 cooperates with other transcription factors including E2F1, E2F4, SP1, NF-kB, NF-Y, and ZEB1 to promote expression of its target genes [43]. Cordani et al. showed that mutant p53 interacted 
with NF- $\mathrm{kB}$ p50 subunit, as a transcriptional repressor, and mutant p53/p50 complex was recruited onto the promoter of ATG12, an essential mediator of the formation of autophagosomal membrane, to inhibit autophagy [40]. Conversely, mutant p53 proteins are degraded by autophagy-dependent mechanism, instead of MDM2dependent proteasomal degradation in physiological conditions [44], maybe resulting from the increased of mutant p53 stability [45].

\section{Mitogen-activated protein kinase (MAPK)-related pathways}

Among mitogen-activated protein kinase (MAPK) family members, JNK and p38 MAPK (p38) are generally considered to induce cell growth arrest and apoptosis in response to the various extracellular stimuli, while extracellular signal-regulated kinase (ERK) activated by growth factors promotes cell proliferation and transformation [46]. JNK regulates autophagy through two distinct modes: on the one hand, the activation of JNK1, but not JNK2, phosphorylates Bcl-2 on multiple sites induced by starvation to dissociate it from Beclin1, which induces autophagy activation [26]. However, exposed to palmitic acid (PA) and hypoxic stress, it's JNK2, not JNK1 promotes the induction of autophagy, most likely by its upstream protein kinase $\mathrm{C} \mu(\mathrm{PKC} \mu)$ [47] and downstream adaptor protein p62 [48], labeling cytoplasmic cargo for autophagic degradation. Conversely, a recent study showed that targeted deletion of JNK1, JNK2 and JNK3 in neurons increased autophagy by a FOXO1/ BNIP3/Beclin1 pathway, concomitantly increasing the expression of proapoptotic protein Bim [49]. On the other hand, the activated JNK can phosphorylate and then activate the transcription factor c-Jun/c-Fos, which transactivates the Beclin1 to induce autophagy [50]. Notably, as another key downstream transcription factors of JNK, FOXO transcribes multiple ATG genes to regulate autophagy. For instance, FOXO1 controls the transcription of VPS34 and ATG12, which involve in the autophagic initiation [51]. FOXO3 alters the transcription of many autophagy-related genes, including LC3, BNIP3, Beclin1, ULK2, ATG4b and ATG12L $[52,53]$.

In addition to inducing apoptosis, p38 MAPK also plays a dual role in the regulation of autophagy in response to chemotherapeutic agents. As a positive regulator, p38 MAPK signaling pathway regulates IFNy-induced macrophage autophagy [54]. Under oxidative stress, the activity of $\mathrm{p} 38 \alpha / \beta$ MAPK elicits the expression of ATG7 to regulate the autophagy-lysosome systems in muscle wasting [55]. As a negative regulator, phosphorylation of ATG5 at threonine 75 by the Gadd45 $\beta$-MEKK4-p38 pathway inhibits starvation-induced autophagy [56]. Moreover, in senescent $\mathrm{CD}^{+} \mathrm{T}$ cells, p38 MAPK blockade induces an increase in autophagy to achieve the additional energy through enhanced interactions between p38 interacting protein (p38IP) and ATG9 [57]. As reported, some separate investigations have showed that aberrant ERK activation can promote autophagy in certain conditions. During starvation, ERK2 regulates nuclear localization and activity of TFEB, a master gene for lysosomal biogenesis, which significantly increases the number of autophagosomes [58]. Also, a recent study reported that ERK8 induces autophagy via interacting with LC3 and GABARAP [59]. Conversely, ERK1/2 inhibition activates the signaling axis LKB1/AMPK/ULK1 to stimulate autophagy in pancreatic ductal adenocarcinoma [60,61]. As a speculation, the dual role of p38 MAPK and ERK pathway, depending on the cell types and stimulus, may control the balance between apoptosis and autophagy in response to genotoxic stress.

\section{Metabolic stress-induced signaling}

The accumulation of unfolded proteins in endoplasmic reticulum (ER) causes ER stress and triggers the unfolded protein response (UPR), which orchestrates the recuperation of ER function. UPR are initiated by three protein sensors located on the membrane of ER, namely inositol-requiring enzyme $1 \alpha$ (IRE1 $\alpha$ ), activating transcription factor 6 (ATF6) and protein kinase R-like endoplasmic reticulum kinase (PERK), which are also in charge of the autophagy induced by ER stress (Fig. 3). IRE1 $\alpha$ binds to TNF receptor-associated factor 2 (TRAF2), which then recruits and activates apoptosis signal-regulating kinase 1 (ASK1) [62]. Subsequently, ASK1 activates the JNK and p38 pathway during ER stress $[63,64]$. Also, IRE1 $\alpha$-induced splicing of XBP1 negatively regulates the transcription factor FOXO1 by inhibiting its expression [65], and by interacting with FOXO1 to direct it toward proteasome-dependent degradation [66]. As a transcription factor, ATF6 interacted with transcription factor C/EBP- $\beta$ is obligatory for death-associated protein kinase 1 (DAPK1) expression, which controls apoptosis and autophagy [67]. Other report has proved that DAPK1 modulates mATG9a trafficking during quinocetone treatment [68]. DNA-damage-inducible transcript 3 (DDIT3) activated by ATF6 upregulates LC3B expression by directly binding to its promotor region [69]. Moreover, the protein kinase PERK directly phosphorylates eIF $2 \alpha$ and then specifically upregulated transcription factors ATF4 and its downstream target protein C/EBP-homologous protein $(\mathrm{CHOP})$ to induce the expression of Beclin1, ATG5, ATG12 and the conversion of LC3B-I to LC3B-II [69-71]. The proapoptotic transcription factor $\mathrm{CHOP}$ acts the changeover switch between autophagy and apoptosis in the PERK pathway, because the inhibition 


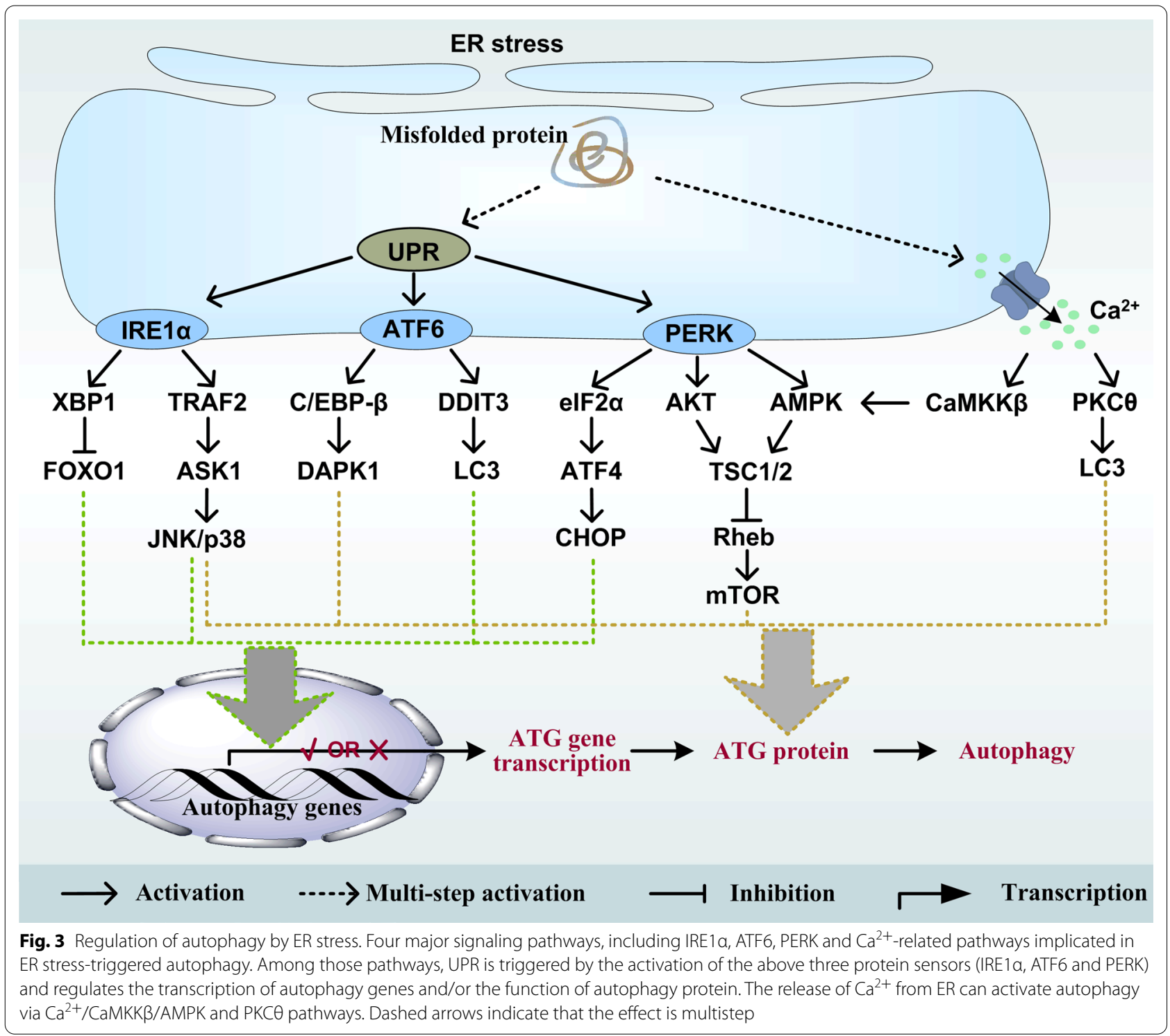

of CHOP stimulates autophagy and suppresses apoptosis under ER stress [72]. Notably, the activation of PERK also stimulates the AKT- and AMPK-related signaling pathway to trigger autophagy $[73,74]$. In addition to UPR, ER stress leads to the release of stored $\mathrm{Ca}^{2+}$ from ER to the cytosol in a free form, which could activate various protein kinases, as regulators of autophagy signaling. An increase in free cytosolic $\mathrm{Ca}^{2+}$ induced by $\mathrm{Ca}^{2+}$ mobilizing agents (ionomycin, ATP, thapsigargin and vitamin D compounds) activates $\mathrm{Ca}^{2+} /$ calmodulindependent protein kinase kinase- $\beta$ (CaMKK $\beta$ )-AMPKTSC1/2-Rheb-mTORC1 signaling pathway and finally initiates autophagy [75]. $\mathrm{Ca}^{2+}$-dependent PKC $\theta$ activation is localized to LC3-containing dot structures and induces autophagy in response to ER stress [76].
Hypoxia, another metabolic stress, also induces autophagy in numerous normal and cancer cells under hypoxia $\left(1 \% \mathrm{O}_{2}\right)$ and severe hypoxia $\left(0.1 \% \mathrm{O}_{2}\right)$ conditions. In $1 \%$ hypoxia, autophagy is triggered through HIF-inducted BNIP3 and BNIP3L, which interact with Bcl-2 via their atypical BH3-domains [77, 78] (Fig. 2), and subsequently disrupt the association of Beclin1 and $\mathrm{Bcl}-2$ [79]. In $<0.01 \%$ hypoxia, oxygen deprivationinduced autophagy in tumor cells is not dependent on HIF signaling and its target gene products BNIP3 and BNIP3L, but is supported by AMPK activity [80]. Alternatively, the UPR is activated by severe hypoxia to facilitate autophagy through regulating PERK/eIF2 $\alpha /$ ATF4/ $\mathrm{CHOP}$ pathway and then increasing transcription of the essential autophagy genes LC3 and ATG5 [81]. 
Thus, hypoxia signals can enter the energy metabolism and ER stress pathways to regulate autophagy, achieving maximum cell survival.

Accumulation of reactive oxygen species (ROS) and reactive nitrogen species (RNS) could cause oxidative stress, as an important inductor of autophagy, and there are characteristically high levels of ROS and RNS in cancer cells because of malfunction of the mitochondrial electron transport chain. Laura PoilletPerez et al. have showed that ROS are essential for autophagy and directly oxidize the cysteine protease ATG4, which subsequently is inactivated to promote lipidation of ATG8 and autophagosome formation [82]. As reported, ROS specifically induce lysosomal $\mathrm{Ca}^{2+}$ release and then activate calcineurin-dependent TFEB-nuclear translocation, which regulates lysosome biogenesis and autophagy [83]. Notably, both high levels of ROS and RNS increase the activation of AMPK $[84,85]$ and MAPK $[86,87]$ to induce autophagy. However, the reduction of ROS/RNS accumulation will cause inhibition of autophagy [88]. ROS/RNS may specifically regulate these processes of pro-autophagy and anti-autophagy depending on their amount or cellular content.

\section{MicroRNA-triggered signaling}

MicroRNAs (miRNAs) are small non-coding RNAs, which interact with targeted mRNAs mainly at their $3^{\prime}$ untranslated regions (UTR) and silence the gene expression in a post-transcriptional fashion. In the induction stage of autophagy, miRNA-106a and miRNA-885-3p exert their anti-autophagic function via targeting ULK1 [89], and ULK2 [90] respectively, and then impede autophagy induction (Fig. 4). In the second stage, various miRNAs, including miRNA-30a, miRNA-376b and miRNA-519a, target Beclin1 and reduce the autophagy activity of tumor cells induced by cisplatin $[33,91]$, rapamycin [92], and imatinib [93]. Moreover, miRNA-374a and miRNA-630 directly suppress autophagy by decreasing the expression of UVRAG, a component of the initiation complex [33]. In the third stage, miRNA-101 inhibits etoposide- and rapamycin-induced autophagy through targeting ATG4D [94], which inhibits the conversion of LC3-I to LC3-II. The protein levels of ATG5 are also dramatically reduced by miRNA-30a [93], miRNA181a and miRNA-374a [33] to block autophagic signaling. Another main LC3 homolog, LC3B, is directly regulated by miRNA-204 in clear cell renal cell carcinomas [95]. In the stage of fusion and degradation, targeted RAB5A by miRNA-101 to block autophagosome-lysosome

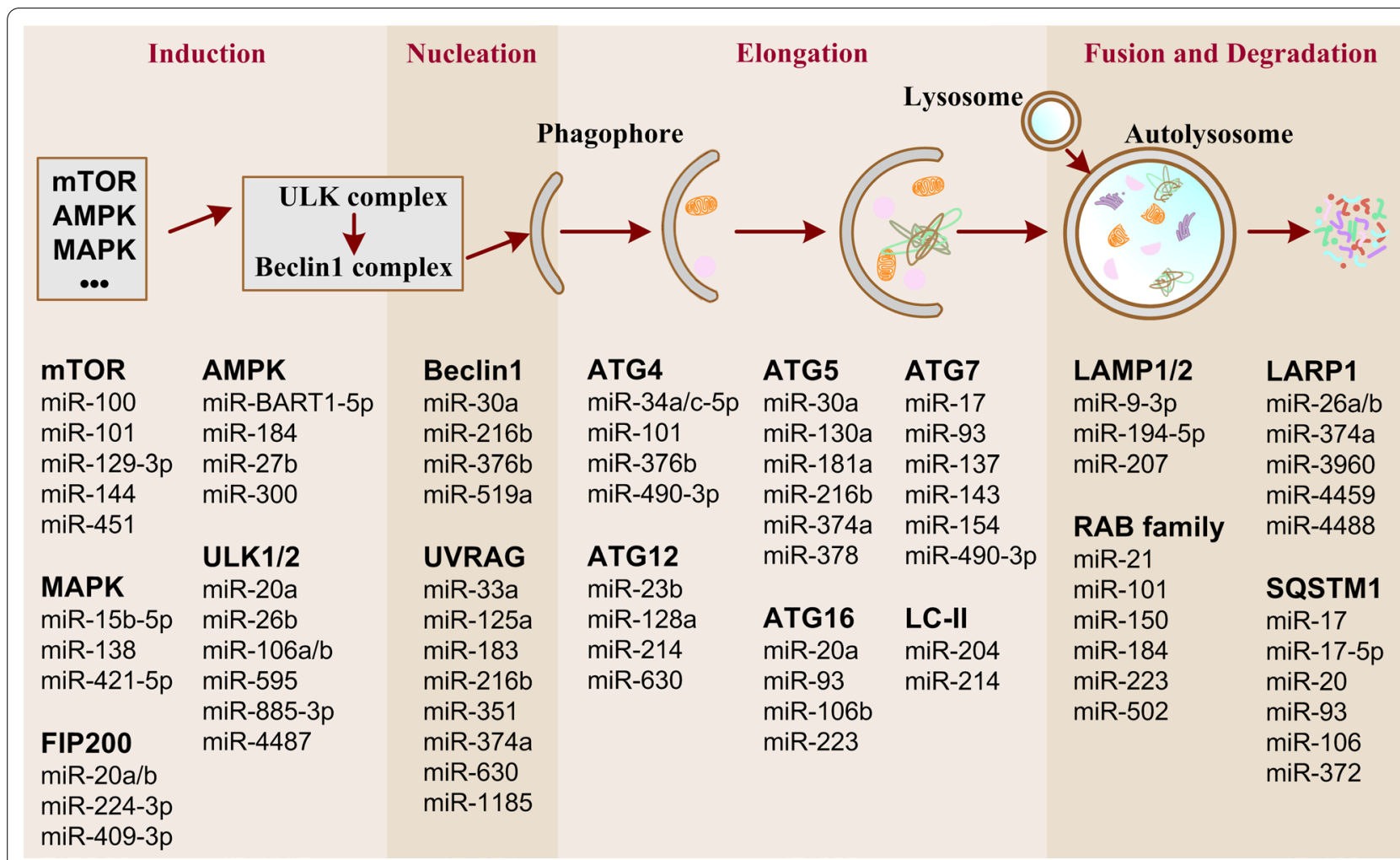

Fig. 4 Overview of the miRNAs and specific targets involved in the regulation of autophagy at different stages 
fusion also inhibits etoposide- and rapamycin-induced autophagy [94]. miRNA-106 and miRNA-372 are identified as direct regulators of p62 [96, 97], which binds to LC3 to degrade the ubiquitinated protein aggregates in autophagolysosome.

miRNAs also target the mRNA of some genes in other signaling pathways. miRNA-146a increased by HIF- $1 \alpha$ but not HIF- $2 \alpha$ promotes hypoxia-induced autophagy through Bcl-2 [98]. miRNA-495-3p modulates the target gene GRP78 and its downstream mTOR to inhibit multidrug resistance in gastric cancer [99]. Moreover, the expression of DUSP4 and DUSP5, two negative regulators of MAPKs, is suppressed by miRNA-26a though directly interacting with their $3^{\prime}$-UTRs, which then boosts cytoprotective autophagy in the liver [100]. As upstream of mTOR and MAPKs, epidermal growth factor receptor (EGFR) expression is inhibited by miRNA-7 to induce autophagic cell death in human cancer cells [101]. p53-related signaling is also regulated by miRNA. For instance, miRNA-502 suppresses autophagy via a negative feedback regulatory loop of p53 in colon cancer [102].

\section{Long noncoding RNA-triggered signaling}

Distinct from miRNA, long noncoding RNAs (lncRNAs) are longer than 200 nucleotides and their length with an advantage to bind target molecules at multiple sites in three-dimensional structures contributes to the complexity of signal network regulation composed of DNA, RNA and protein. Currently, accumulating evidence has indicated that lncRNAs participate in the regulating networks of autophagy by mediating the transcriptional and post-transcriptional regulation of autophagy-related genes. LncRNA growth arrest-specific 5 (GAS5) activates autophagy to inhibit breast cancer proliferation, invasion and formation via upregulating ULK1/2 protein levels [103]. In uveal melanoma, tumorigenesis is inhibited by IncRNA ZNNT1-induced autophagy through upregulating ATG12 expression [104]. However, activated autophagy by lncRNA also promotes tumorigenesis and drug resistance. LncRNA nuclear-enriched abundant transcript 1 (NEAT1) activates autophagy via regulating ATG3 or Beclin1 expression and inhibits chemotherapeutic efficacy in hepatocellular carcinoma (HCC) [105] and colorectal cancer [106]. In breast cancer, activated autophagy by lncRNA H19, an imprinting lncRNA, contributes to tamoxifen resistance via upregulating Beclin1 expression [107]. One additional study indicated that lncRNA human plasmacytoma variant translocation 1 (PVT1) induces autophagy through increasing the protein and mRNA levels of Pygo2 and ATG14 and enhances cell resistance to gemcitabine in pancreatic cancer [108].
Conversely, some lncRNAs have exerted the effect of inhibiting autophagy to influence the occurrence and development of tumor. LncRNA cancer susceptibility candidate 9 (CASC9) suppresses autophagic cell death via the $A K T / m T O R$ signaling and cell proliferation and tumor progression in oral squamous cell carcinoma [109]. LncRNA colon cancer-associated transcript-1 (CCAT1) is closely associated with a variety of cancers. A recent study has clearly shown that IncRNA CCTA1 induced autophagy inhibition for cell survival via increasing PI3K/ AKT pathway in podocytes [110]. LINC00470, known as C18orf2, also activates AKT signaling, inhibits cell autophagy and promotes glioblastoma cell tumorigenesis and poor patient prognosis [111]. Beyond that, inhibited autophagy by lncRNAs could also limit tumor growth. In 42 tumor samples, lncRNA clarin 1 antisense RNA 1 (CLRN1-AS1) was downregulated compared to normal samples, and it abrogated prolactinoma cell proliferation by inhibiting autophagy in the way of $\mathrm{Wnt} / \beta$-catenin signal deactivation [112]. Additionally, activated PI3K/ AKT/mTOR signaling pathway and inactivated Beclin1 by lncRNA maternally expressed gene 3 (MEG3) inhibited autophagy and contributed to the cytotoxicity of adenosine in hepatoma HepG2 cells [113]. As discussed above, lncRNAs and autophagy have cross-regulation and dual effects on tumor because lncRNAs can increase or decrease autophagy, and the altered autophagy can further promote or inhibit tumor growth.

\section{Dual role of autophagy in tumor drug resistance}

Autophagy plays a housekeeping role by recycling unnecessary proteins and damaged organelles in normal cells. In this regard, recycling by autophagy predictably provides a survival advantage to tumor cells during tumorigenesis. However, persistent and excessive autophagy could unexpectedly lead to caspase-independent autophagic cell death. Thus, autophagy induced by metabolic and therapeutic stresses, potentially inducing drug resistance, has a dual role as guarder and executioner with additional survival and death mechanisms.

\section{Autophagy as a guardian in tumor drug resistance}

Extensive studies indicate that the upregulated autophagy not only enhances the survival of tumor, but also enhances the drug resistance of tumor in a wide range of tumor types. Although the mechanisms by which autophagy promotes tumor drug resistance are not fully understood, important clues are emerging. Apparently, autophagy induced by therapeutic agents supports tumor cell metabolism by recycling damaged proteins and organelles and then prevents DNA damage, as a result of inducing cancer drug resistance [114]. Recently, a direct evidence has 
been showed that the induction of autophagy-regulated DNA damage response via ataxia telangiectasia mutated (ATM)-mediated activation of DNA-dependent protein kinase catalytic subunit (DNA-PKcs) and poly(ADP-ribose) polymerase (PARP)- 1 in response to capsaicin [115]. An enhanced DNA damage response is also induced by autophagy via homologous recombination (HR) repair pathway, which is a major way of repairing double-strand breaks [116]. Moreover, the stimulated autophagy induced by epirubicin (EPI) can increase drug efflux by P-glycoprotein (P-gp), encoded MDR genes which reduce intracellular concentrations of drugs, and downregulate the NF- $\mathrm{kB}$ signaling pathway, which decreases the rate of apoptosis, and thereby cause EPI resistance [117]. Another key protein encoded by MDR genes, multidrug resistanceassociated protein 1 (MRP1) is also upregulated by ER stress-triggered autophagy for increasing intracellular drug efflux [118]. Aldehyde dehydrogenase 1A3 (ALDH1A3), as a detoxifying enzyme to drive acquired drug resistance, is also regulated by autophagy during temozolomide treatment [119]. As a prototypical damage-associated molecular pattern (DAMP) molecule, high-mobility group B1 (HMGB1) is released by the induced autophagy [120,121], and promotes drug resistance in ovarian cancer [122], colorectal cancer [123] and lung cancer [124]. Thus, autophagy-mediated drug resistance is a multifactorial phenomenon involving cytoplasmic material renew, gene repair, alterations in drug concentration and metabolism and changes in the expression or activity of key protein.

Of particular importance, the development of drug resistance also involves the changes of apoptotic and survival signals. In tumor necrosis factor (TNF)related apoptosis-inducing ligand (TRAIL)-resistant cells, the cytoprotective autophagy degrades a subunit of the active caspase- 8 enzyme, an executive protein on mitochondrial apoptosis pathway [125]. p53, as a tumor suppressor, activates autophagy, whereas the activated autophagy in turn suppresses p53 [114]. As mostly reported, the induced autophagy is accompanied by the disruption of the Beclin $1 / \mathrm{Bcl}-2$ complex, and then Bcl-2 is released from the complex to enhance cell survival [126]. In this regard, the three types of molecular changes may also involve in autophagy promoting drug resistance: inactivation of proapoptotic factors, activation of antiapoptotic effectors and enhancement of survival signals. Namely, autophagy increases stress-induced damage threshold to buffer therapeutic stress and eliminates the signals of apoptosis, which both are required to induce cell death, thereby confers tumor resistance to apoptosis.

\section{Autophagy as an executioner in tumor drug resistance}

Besides cell survival, autophagy can also induce cell death, namely autophagic cell death, caused by prolonged or sustained autophagy, which is defined as type II cell death preceded or accompanied by the large-scale autophagic vacuolization in cytoplasm and the resultant vacuolated appearance independent of apoptosis (type I cell death) and necrosis (type III cell death). Overexpression of autophagy genes may be a major factor in the death execution process by autophagy. For instance, enforced expression of Beclin1 induces excessive autophagy and promotes death of SW982 human synovial sarcoma cells [127]. The accumulation of p62/ SQSTM1 induced by plant phytoalexin resveratrol triggers autophagic cell death in imatinib-resistant chronic myelogenous leukemia (CML) cells [6]. Additionally, the ATG5-ATG12 complex also accumulates to induce autophagic cell death in metformin-treated ovarian cancer cells [128]. Thus, autophagic cell death driven by autophagy genes is context-dependent and also induced in apoptosis-resistant cells, particularly in pro-apoptotic protein deficient cells. Moreover, autophagic cell death can be served as an alternative cell death approach when cells fail to undergo apoptosis, even in the drug resistance of tumor.

Signaling thresholds may be another crucial factor that dictates whether the autophagy trends the role of pro-survival or pro-death. The intensity of oncogenic Ras signaling is related to the outcome of senescence or autophagic cell death. Enforced expression of Ras upregulates the BH3-only protein Noxa as well as Beclin1 to promote autophagic cell death [129]. Overexpression prolidase induces massive autophagy that leads to cell death via upregulating ATG7, LC3A/B and Beclin1 [130]. Additionally, multiple signal pathways are activated at the same time to achieve the goal of excessive autophagy. Baicalein, a flavonoid with well-established anticancer properties, activates AMPK/ULK1 and downregulates mTORC1 complex components to induce autophagic cell death [7]. Notably, the high expression of caspase-10 and $\mathrm{cFLIP}_{\mathrm{L}}$ in myeloma cells inhibits autophagic cell death by cleaving and inactivating BCLAF1, encoding Bcl2associated transcription factor 1 [131]. The explanation for such discrepancies (pro-survival and pro-death using the same set of autophagy equipment) is a quantitative relationship in which upstream signaling molecules affect cellular responses by controlling the relative threshold of autophagy flux in response to external stimuli. Improved autophagy flux over the threshold (autophagic cell death) or decreased autophagy flux (blocking autophagy for survival) may be a novel strategy to treat tumor in autophagy-mediated drug resistance. 


\section{Targeting autophagy against tumor drug resistance}

Tumor therapeutic drugs primarily act by inducing apoptosis to kill cells. Based on the above description, basic autophagy protects cancer cells from chemotherapy, leading to drug resistant and even refractory cancer against the induced apoptosis. However, a high level of autophagy occurs for sustained or excessive metabolic cycle of intracellular components, which leads to excessive removal of essential proteins and cellular organelles, and finally causes caspase-independent autophagic cell death with benefit for the treatment of therapeutic drugs (Fig. 5).

\section{Autophagy inhibition facilitates the therapeutic efficiency} As therapeutic drug-promoted autophagy is supported by abundant substantial evidence, a new therapeutic strategy considering a combination with inhibiting autophagy has been proposed. Currently, studies to inhibit autophagy commonly employ the approaches of genetic silencing of ATGs and pharmacological inhibitors. Gene silencing using small interfering RNA (siRNA) usually knocks down Beclin1, ATG5, ATG7, ATG8 and ATG12 to inhibit autophagy and sensitizes the drug-resistant cancers [132-135], while pharmacological inhibitors generally use 3-methyladenine (3-MA), bafilomycin A1
(BafA) and chloroquine (CQ) to inhibit the formation of autophagosome [132-134, 136] and sensitize the resistant cancer cells to chemotherapy. 3-MA is an inhibitor of class III PI3K, VPS34, and thus it inhibits autophagy at an early stage. In contrast, BafA, a vacuolar $\mathrm{H}^{+}$-ATPase inhibitor, and $\mathrm{CQ}$, a fusion inhibitor of autophagosome and lysosome, are in the late stage of autophagy to block cargo degradation.

Specific chemical inhibitors of receptor tyrosine kinase/Class I PI3K/AKT/mTOR pathway have been shown to be effective anti-tumor therapies. Imatinib and dasatinib, as tyrosine kinase inhibitors, are the standard treatments for CML, but a great many of patients don't respond effectively. Pharmacologically blocking autophagy using CQ, or silencing of ATG5 and ATG7, could significantly enhance imatinib-resistance CML cell death $[132,136]$. Dasatinib combined with autophagy inhibitors resulted in almost complete disappearance of phenotypical and functional CML stem cells [136]. As the dual Class I PI3K/mTOR inhibitor, NVP-BEZ235, synergized with autophagy inhibitors promotes apoptosis of drug-resistant tumors [133, 134]. Perifosine is an alkylphospholipid to inhibit AKT activity and exhibit antitumor activity. The combination of perifosine with $\mathrm{CQ}$ or $\mathrm{NH}_{4} \mathrm{Cl}$ enhanced apoptosis and the inhibition of tumor growth [137]. In clinical phase I

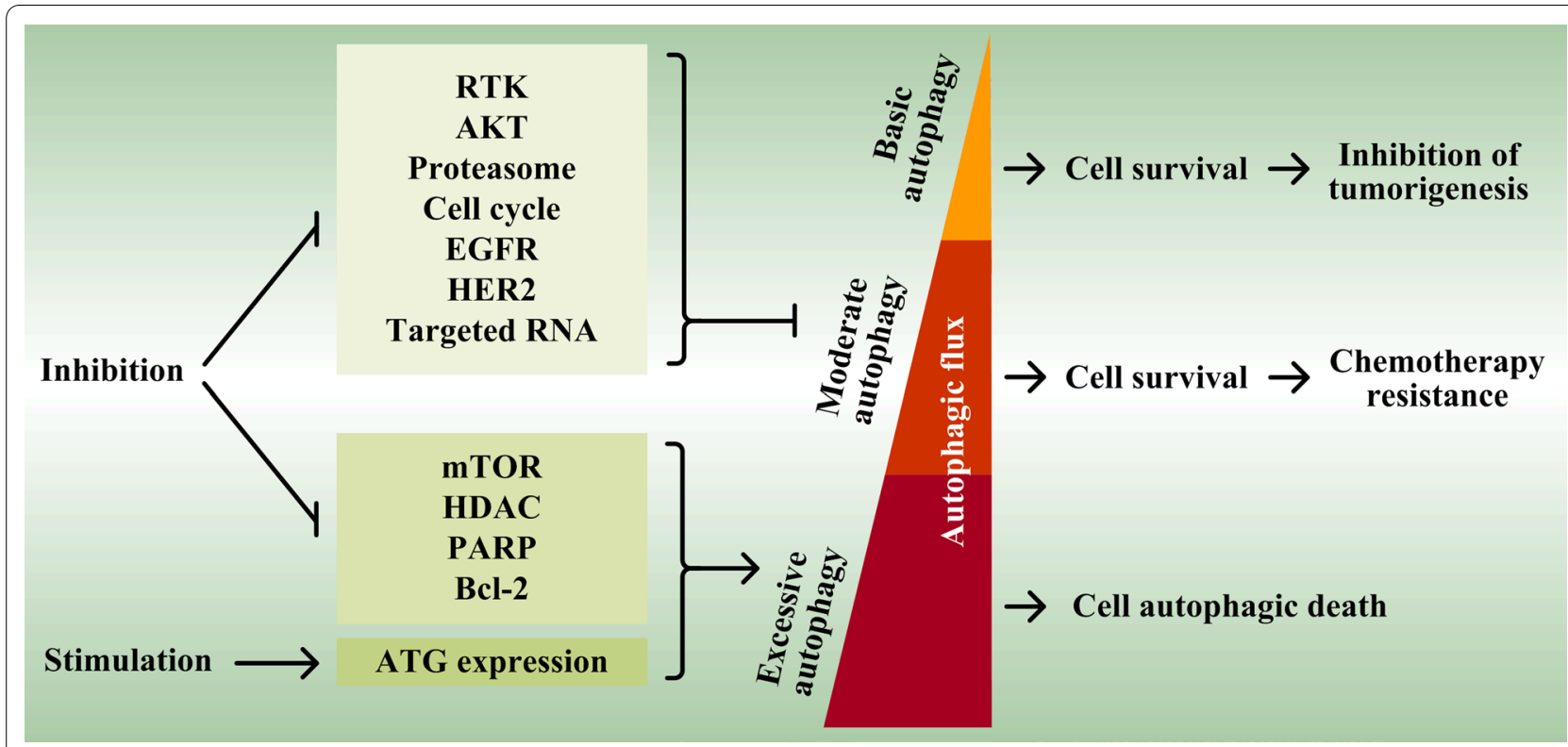

Fig. 5 Employing autophagy against tumors. Basic autophagy recycles dysfunctional or unnecessary proteins and damaged or aged cellular organelles to provide constituent metabolites for cells, and inhibits tumorigenesis. The induction of moderate autophagy by drugs, which possess a higher autophagic flux and triggers drug resistant and even refractory cancer against the induced apoptosis, can be repressed by some chemical inhibitors or therapeutic antibodies (such as RTK inhibitors, AKT inhibitors, proteasome inhibitors, cell cycle inhibitors, miRNA, and EGFR and HER2 therapeutic antibodies). Conversely, other inhibitors (such as mTOR inhibitors, HDAC inhibitors, PARP inhibitors and Bcl-2 inhibitors) and enforced expression of ATG (such as ATG3, ATG4, ATG5, ATG9 and Beclin1) further improve autophagic flux and lead to cell autophagic death due to the excessive autophagy 
trial, the combination of mTOR inhibitor temsirolimus and autophagy inhibitor hydroxychloroquine (HCQ), augmented cell death in patients with advanced solid tumors and melanoma [138]. The above discussion shows that the same effect can be achieved at any step in the suppression of receptor tyrosine kinase/Class I $\mathrm{PI} 3 \mathrm{~K} / \mathrm{AKT} / \mathrm{mTOR}$ pathway combined with autophagy inhibition. However, choosing which step in the pathway for combination therapy may need to consider tumor type and stage of tumor development.

Preclinical models showed that some proteasome inhibitors stimulated autophagy by the accumulation of misfolded proteins, namely ER stress. In agreement with the viewpoint, the inhibition of proteasome inhibitor (bortezomib and NPI-0052)-induced autophagy using 3-MA or CQ increased the levels of cell death in prostate cancer cell model [139]. Compared with wild-type animals, proteasome inhibitor epoxomicin exhibited an enhanced antitumor function in autophagydefective Beclin $^{+/-}$mice [135]. The next-generation proteasome inhibitors carfilzomib and oprozomib also induced autophagy and enhanced cell death when used with autophagy inhibitor CQ in head and neck squamous cell carcinoma tumor [140]. CQ stimulates a slow protein accumulation, localized to lysosomes, while bortezomib induces a rapid buildup of proteins where aggresome formation is in the cytosol [141]. The accumulation events often lead to mitochondrial disorder, accompanied by the release of cytochrome $c$ and the activation of Apaf-1 containing apoptotic complex [142]. Thus, the combination of proteasome inhibition with autophagy inhibition can achieve stronger antitumor effect.

Cell cycle-mediated drug resistance is described that tumor cells are relatively insensitive to chemotherapeutic drugs because the cell cycle is the mechanism by which cells are divided. Through inducing G2 and $M$ phase arrest and inhibiting cell division, isoliquiritigenin has showed antitumor effect in a variety of tumors [143]. Using 3-MA to suppress autophagy induced by isoliquiritigenin enhances its antitumor activity in ES-2 cells [143]. In most cancer cell types, silibinin also causes cell cycle arrest, resulting in cell apoptosis [144]. Likewise, inhibition of autophagy increases silibinin-induced SW480 and SW620 cell death [145]. Another important anti-cell cycle chemotherapeutic agent, vincristine, induces apoptosis of gastric cancer cells, and siRNA knock-down Beclin1 or ATG5 sensitizes vincristineresistance tumor cells [146]. Maybe the most interesting aspect of those drugs that inhibit cell cycle is how they initiate protective autophagy with one or more specific signal pathway(s) in various cell types. This will be more conducive to remove the drug resistance of tumors by autophagy.
Cetuximab, a therapeutic antibody that blocks the function of epidermal growth factor receptor, induced apoptosis and autophagy, and the knockdown of ATG7 or Beclin1 or treatment with CQ sensitized cancer cells to cetuximab-triggered apoptosis [147]. Mechanistically, cetuximab acted by downregulating Bcl-2 to promote the association between Beclin1 and VPS34. Human epidermal growth factor receptor 2 (HER2) is highly expressed in a variety of cells, such as breast carcinomas [148], colon cancer [149] and stomach adenocarcinoma [150]. Trastuzumab, as a humanized monoclonal antibody binding to domain IV of HER2, is approved by FDA for the treatment of HER2-positive breast and stomach adenocarcinoma/gastroesophageal junction adenocarcinoma cancer (https://www.cancer.gov/about-cancer/ treatment/drugs/trastuzumab). The state of "autophagy addiction" also occurs in trastuzumab-resistant tumor cells. However, targeted genetic ablation of ATG5, ATG8 or ATG12 notably reduces the intrinsic refractory of trastuzumab [148]. Table 1 presents several examples of therapeutic anti-cancer antibodies, their targets and primary indications. These reports indicate that combined targeting autophagy can enhance the anti-cancer effect of the therapeutic antibodies.

As another important therapeutic strategy, miRNAs have been shown to regulate drug resistance in a wide variety of cancers. miR-23b-3p inhibited autophagy to sensitize vincristine-resistant gastric adenocarcinoma cell SGC7901 via decreasing the expression of ATG12 [161]. miRNA-29c inhibiting autophagy mediated by USP22 increased the gemcitabine-induced pancreatic cancer cell apoptosis [162]. Another recent study [163] showed that miR-409-3p ameliorated the sensitivity of ovarian cancer cells to cisplatin by interrupting the FIP200-mediated autophagy. However, all of them have been found to be downregulated in tumors, which may be one mechanism to result in drug resistance. Also, overcoming drug resistance by using miRNA to target autophagy may prove to be tempting and promising.

\section{Inducing autophagic cell death overcomes drug resistance}

A large number of studies have shown that autophagy is necessary to effectively kill tumor cells in certain circumstances. Autophagy in this case is called autophagic cell death, which is regarded as cell death with autophagy rather than cell death by autophagy. Indeed, some drugs, such as rapamycin, bortezomib and butyrate to promote autophagosome formation [164, 165], and enforced expression of the autophagy-related genes, such as ATG3, ATG4 [166], ATG5 [164, 165], ATG9 [167] and Beclin1 [127], are demonstrated to induce autophagic cell death, and work in tandem with other chemotherapeutic drugs to conquer cancer in certain cell types. 
Table 1 Summary of therapeutic antibodies combined with inhibition of autophagy

\begin{tabular}{|c|c|c|c|c|}
\hline Therapeutic antibodies & Targets & Combination therapy & Indications & References \\
\hline Rituximab & CD20 & $\mathrm{CQ}$ & Non-Hodgkin lymphoma & {$[151]$} \\
\hline Bevacizumab & VEGF & CQ & $\mathrm{HCC}$ & [152] \\
\hline \multirow[t]{4}{*}{ Cetuximab } & EGFR & CQ & Vulvar squamous carcinoma & [147] \\
\hline & & Overexpressed Bcl-2 & Colorectal adenocarcinoma & \\
\hline & & siRNA ATG7 & Lung adenocarcinoma & \\
\hline & & siRNA Beclin1 & & \\
\hline \multirow[t]{2}{*}{ Gemtuzumab ozogamicin } & CD33 & PP242 & Acute myeloid leukemia & [153] \\
\hline & & AZD2014 & & {$[154]$} \\
\hline DN30 & Met & Baf & Cardiomyoblasts & [155] \\
\hline \multicolumn{5}{|l|}{ DO24 } \\
\hline Trastuzumab & HER2 & CQ & Breast cancer & [148] \\
\hline Milatuzumab & CD74 & FTY720 & Mantle cell lymphoma & [156] \\
\hline \multirow[t]{3}{*}{ Tositumomab } & CD20 & Overexpressed Bcl-2 & B cell malignancies & [157] \\
\hline & & siRNA Beclin1 & & \\
\hline & & siRNA ATG 12 & & \\
\hline \multirow[t]{2}{*}{$\mathrm{CH} 12$} & EGFRvIII & siRNA ATG7 & $\mathrm{HCC}$ & {$[158]$} \\
\hline & & siRNA Beclin 1 & & \\
\hline$\beta 2 \mathrm{M}$ mAb & $\beta_{2}$-microglobulin & Bortezomib & Multiple myeloma & [159] \\
\hline PD-1 mAb & PD-1 & Pemetrexed + sildenafil & Non-small cell lung cancer & [160] \\
\hline CTLA4 mAb & CTLA4 & & & \\
\hline
\end{tabular}

As described early, mTOR is the central regulator of autophagy and a key target for autophagy regulation. The pharmacological inhibitor rapamycin enhanced isoliquiritigenin-induced autophagic and apoptotic cell death in cancer chemotherapy in adenoid cystic carcinoma cells [164]. The combination of everolimus, another mTOR inhibitor, and propachlor synergistically enhanced cell death by inducing autophagic cell death in prostate cancer cells [168]. Similarly, RAPA, a mTOR inhibitor to induce autophagy, increased cell death in temozolomide-treated U251 glioma cells [169]. However, inhibition of mTOR does not always induce autophagic death, but rather protective autophagy. For instance, given that mTOR inhibitor is a potent inducer of autophagy, HCQ relieved temsirolimus, a mTOR inhibitor, resistance and significantly enhanced antitumor activity with safety and acceptability in cancer patients with advanced solid tumors and melanoma [138]. Currently, the role of autophagy in cancer patients is being studied in multiple clinical trials with mTOR inhibitors (https://www.clini caltrials.gov).

The success of bortezomib, a proteasome inhibitor, has been a standard-of-care therapy for malignancy multiple myeloma [165]. However, bortezomib is not responded in many patients and those patients commonly develop drug tolerance. A recent study shows that enforced expression of the ATG5 overcomes bortezomibresistance hematologic malignancies [165]. A novel proteasome inhibitor marchantin $\mathrm{M}$ could directly trigger autophagic cell death via PI3K/AKT/mTOR pathway in prostate cancer cells [170]. In this regard, induction of sustained autophagy (autophagic cell death) seems to be required to compensate for severely damaged proteasome pathway. Thus, induced autophagic cell death maybe overcomes drug resistance to proteasome inhibitors.

Histone deacetylase (HDAC) is believed to regulate the epigenetic alterations which could restrain tumor suppressor genes and promote tumorigenesis. Consequently, inhibition of HDAC becomes an attractive anti-cancer therapeutic approach. HDAC inhibitor NCO-90/141 increased cell death via cytochrome $c$-mediated apoptosis and caspase-independent autophagic cell death in leukemic cell lines [171]. When apoptosis was inhibited, LAQ824 and panobinostat, two other HDAC inhibitors, triggered autophagic cell death in lymphoma cells and tumor xenograft model [172]. To overcome EGFR tyrosine kinase inhibitor resistance in T790M mutant lung cancer, the combination of suberoylanilide hydroxamic acid (SAHA) and either BIBW2992 or WZ4002, two tyrosine kinase inhibitors, induces autophagic cell death to enhance anti-tumor effect in PC-9G and H1975 cells and mouse xenografts [173]. Summing up the above, autophagic cell death is a way of compensation for cell death when the cells fail to undergo apoptosis.

There are also other specific chemical drugs that induce autophagic cell death and then relieve the resistance to 
therapeutic drugs. For instance, ABT-888, a PPRA inhibitor, increased the therapeutic efficacy of temozolomideresistance glioma cells by inducing autophagic cell death [174]. A small-molecule inhibitor of Bcl-2, (-)-gossypol, triggered autophagic cell death and inhibited the growth of androgen-independent prostate cancer xenografts with high levels of Bcl-2 to resist apoptosis [175]. All of these indicate that induced autophagic cell death, as a strategy of synergistic therapy, can occur in multiple drug resistant tumors to circumvent resistance.

\section{Conclusions}

Clinically, the therapeutic resistance resulting in the frequency of tumor progression is disappointing for all people including researchers and clinicians. It is urgent to clarify the mechanisms by which induce drug resistance of tumors. Autophagy inhibition has been presented to improve antitumor efficacy and overcome therapeutic resistance in various types of tumor cells both in vitro and in vivo, which makes it popular with many researchers. However, with the development of autophagy studies, autophagy shows a dual role of pro-death and pro-survival in tumor therapeutic resistance, which also makes it ambiguous in the eyes of researchers. In established cancers, autophagy increases metabolism to inactivate drug and support drug resistance. Indeed, certain anticancer drugs can also induce excessive or sustained autophagy, which leads to the death of tumor cells. Thus, the effect of autophagy induction on the therapeutic efficacy of therapeutic drugs, to a great extent, depends on the characteristics of treatment, type of tumor and stage of disease.

Systemic therapy with autophagy has been used as the clinical therapy for patients with drug resistance. The following questions still remain to be answered: (1) Do cytotoxic stimuli activate autophagy (related to cell survival) or autophagic cell death? (2) What is the mechanism of autophagy activated by cytotoxic stimuli? (3) How to achieve the optimal combinations by targeting which specific biological molecules in autophagy? (4) Does the combination elicit undesirable side effects in cancer patients after long-term autophagy inhibition or autophagy induction (autophagic cell death)? Due to the complex regulatory mechanisms and effects of autophagy, it provides a broad research space for us to elucidate the mysteries. However, it also requires us to provide valuable information on how autophagy is manipulated during tumor drug resistance in future research.

\footnotetext{
Abbreviations

3-MA: 3-Methyladenine; ALDH1A3: Aldehyde dehydrogenase 1A3; AMBRA-1: Autophagy/Beclin 1 regulator-1; AMPK: Adenosine monophosphate kinase; ASK1: Apoptosis signal-regulating kinase 1; ATF4: Activating transcription factor 4; ATM: Ataxia telangiectasia mutated; BafA: Bafilomycin A1; BH3: BCl-2-homology-3 domain; CaMKKß: Calmodulin-dependent protein
}

kinase kinase- $\beta$; CASC9: Cancer susceptibility candidate 9; CCAT1: Colon cancer-associated transcript-1; CCD: Coiled-coiled domain; C/EBP- $\beta$ : CCAAT/ enhancer-binding protein $\beta ;$ CHOP: C/EBP homologous protein; CLRN1-AS1: Clarin 1 antisense RNA 1; CML: Chronic myelogenous leukemia; CQ: Chloroquine; CTSD: Cathepsin D; DAPK1: Death-associated protein kinase 1; DDIT3/4: DNA damage-inducible transcript 3/4; DRAM: Damage-regulated autophagy modulator; DUSP4/5: Dual-specificity phosphatase 4/5; elF2a: Eukaryotic initiation factor 2a; EPI: Epirubicin; ER: Endoplasmic reticulum; ERK1/2: Extracellular signal-regulated kinase1/2; FAK: Focal adhesion kinase; FIP200: Focal adhesion kinase (FAK) family interacting protein 200; FOXO: Forkhead box O; GAS5: Growth arrest-specific 5; HCQ: Hydroxychloroquine; HDAC: Histone deacetylase; HER2: Human epidermal growth factor receptor 2; HIF: Hypoxia-inducible factor; HMGB1: High-mobility group B1; HSC70: Heat shock cognate 70; INSR: Insulin receptor; JNK: C-Jun N-terminal protein kinase; LAPTM4A: Lysosomalassociated transmembrane protein 4A; LC3-1/II: Microtubule-associated protein I/II light chain 3; LKB1: Liver kinase B1; IncRNAs: Long noncoding RNAs; MAPK: Mitogen-activated protein kinase; MDR: Multidrug resistance; MEFs: Mouse embryonic fibroblasts; MEG3: Maternally expressed gene 3; miR: MicroRNA (miRNA); MMP: Mitochondrial membrane permeabilization; MRP1: Multidrug resistance-associated protein 1; mTOR: Mammalian target of rapamycin; NEAT1: Nuclear-enriched abundant transcript 1; PA: Palmitic acid; PARP: Poly(ADP-ribose) polymerase; P-gp: P-glycoprotein; PKR: Protein kinase R-like endoplasmic reticulum kinase; Ptdlns(3)P: Phosphotidylinositol triphosphate; PTEN: Phosphatase and tensin homolog; PVT1: Plasmacytoma variant translocation 1; Rheb: Ras homolog enriched in brain; RNS: Reactive nitrogen species; ROS: Reactive oxygen species; SAHA: Suberoylanilide hydroxamic acid; siRNA: Small interfering RNA; SQSTM1: Sequestosome1; TPP1:Tripeptidyl peptidase 1; TRAF2: TNF receptor-associated factor 2; TRAIL: TNF-related apoptosis-inducing ligand; TSC: Tuberous sclerosis complex; ULK1/2: Unc-51-like kinase-1/2; UPR: Unfolded protein response; UTR: Untranslated regions; UVRAG: UV radiation resistance-associated gene protein; VPS34:Vacuor protein sorting-34; XBP1: X box-binding protein 1 .

\section{Acknowledgements}

Not applicable.

\section{Authors' contributions}

HCC design the study and wrote de manuscript. ZZZ revised the manuscript. All authors read and approved the final manuscript.

\section{Funding}

This work was supported by the National Natural Science Foundation of China (Nos. 62005085, 81972479, 81772803 and 81772643), Science and Technology Project of Guangzhou (No. 2019050001), Scientific and Technological Planning Project of Guangzhou City (Nos. 201805010002 and 201904010038), Natural Science Foundation of Guangdong province (No. 2019A1515011100).

Availability of data and materials

Not applicable.

Ethics approval and consent to participate

Not applicable.

\section{Consent for publication}

Not applicable.

\section{Competing interests}

None of the authors have competing interest to declare.

\section{Author details}

${ }^{1}$ MOE Key Laboratory of Laser Life Science and Institute of Laser Life Science, College of Biophotonics, South China Normal University, Guangzhou 510631 China. ${ }^{2}$ Guangdong Provincial Key Laboratory of Laser Life Science, College of Biophotonics, South China Normal University, Tianhe District, 55 Zhongshan Avenue West, Guangzhou 510631, China.

Received: 20 October 2020 Accepted: 15 November 2020

Published online: 25 November 2020 


\section{References}

1. Saha T. LAMP2A overexpression in breast tumors promotes cancer cell survival via chaperone-mediated autophagy. Autophagy. 2012;8:1643-56.

2. Li WW, Li J, Bao JK. Microautophagy: lesser-known self-eating. Cell Mol Life Sci. 2012;69:1125-36.

3. Feng YC, He D, Yao ZY, Klionsky DJ. The machinery of macroautophagy. Cell Res. 2014;24:24-41.

4. Li XH, He SK, Ma BY. Autophagy and autophagy-related proteins in cancer. Mol Cancer. 2020;19:12.

5. Eskelinen EL. The dual role of autophagy in cancer. Curr Opin Pharmacol. 2011;11:294-300.

6. Puissant A, Robert G, Fenouille N, Luciano F, Cassuto JP, Raynaud S, Auberger P. Resveratrol promotes autophagic cell death in chronic myelogenous leukemia cells via JNK-mediated p62/SQSTM1 expression and AMPK activation. Cancer Res. 2010;70:1042-52.

7. Aryal P, Kim K, Park PH, Ham S, Cho J, Song K. Baicalein induces autophagic cell death through AMPK/ULK1 activation and downregulation of mTORC 1 complex components in human cancer cells. FEBS J. 2014:281:4644-58.

8. Russell RC, Tian Y, Yuan HX, Park HW, Chang YY, Kim J, Kim H, Neufeld TP, Dillin A, Guan KL. ULK1 induces autophagy by phosphorylating Beclin-1 and activating VPS34 lipid kinase. Nat Cell Biol. 2013;15:741-50.

9. Carlsson SR, Simonsen A. Membrane dynamics in autophagosome biogenesis. J Cell Sci. 2015;128:193-205.

10. Pavlinov I, Salkovski M, Aldrich LN. Beclin 1-ATG14L protein-protein interaction inhibitor selectively inhibits autophagy through disruption of VPS34 complex I. J Am Chem Soc. 2020;142:8174-82

11. Maksoud AIA, Elebeedy D, Abass NH, Awad AM, Nasr GM, Roshdy T, Khalil H. Methylomic changes of autophagy-related genes by Legionella effector Lpg2936 in infected macrophages. Front Cell Dev Biol. 2020;7:390

12. Hao J, Li SY, Shi XX, Qian ZQ, Sun YJ, Wang DJ, Zhou XY, Qu HX, Hu SH, Zuo EJ, et al. Bone marrow mesenchymal stem cells protect against n-hexane-induced neuropathy through beclin 1-independent inhibition of autophagy. Sci Rep. 2018;8:4516.

13. Jung $\mathrm{CH}$, Jun CB, Ro SH, Kim YM, Otto NM, Cao J, Kundu M, Kim DH. ULK-Atg13-FIP200 complexes mediate mTOR signaling to the autophagy machinery. Mol Biol Cell. 2009;20:1992-2003.

14. Yuan HX, Russell RC, Guan KL. Regulation of PIK3C3/VPS34 complexes by MTOR in nutrient stress-induced autophagy. Autophagy. 2013:9:1983-95.

15. Niture S, Gyamfi MA, Lin MH, Chimeh U, Dong XL, Zheng WF, Moore J, Kumar D. TNFAIP8 regulates autophagy, cell steatosis, and promotes hepatocellular carcinoma cell proliferation. Cell Death Dis. 2020;11:178.

16. Jia JY, Abudu YP, Claude-Taupin A, Gu YX, Kumar S, Choi SW, Peters R, Mudd MH, Allers L, Salemi M, et al. Galectins control MTOR and AMPK in response to lysosomal damage to induce autophagy. Autophagy. 2019:15:169-71.

17. Efeyan A, Zoncu R, Chang S, Gumper I, Snitkin H, Wolfson RL, Kirak $\mathrm{O}$, Sabatini DD, Sabatini DM. Regulation of mTORC1 by the Rag GTPases is necessary for neonatal autophagy and survival. Nature. 2013:493:679-83.

18. Sancak Y, Bar-Peled L, Zoncu R, Markhard AL, Nada S, Sabatini DM. Ragulator-Rag complex targets mTORC 1 to the lysosomal surface and is necessary for its activation by amino acids. Cell. 2010;141:290-303.

19. Lacher MD, Pincheira R, Zhu Z, Camoretti-Mercado B, Matli M, Warren RS, Castro AF. Rheb activates AMPK and reduces p27Kip1 levels in Tsc2null cells via mTORC1-independent mechanisms: implications for cell proliferation and tumorigenesis. Oncogene. 2010;29:6543-56.

20. Choi H, Merceron C, Mangiavini L, Seifert EL, Schipani E, Shapiro IM, Risbud MV. Hypoxia promotes noncanonical autophagy in nucleus pulposus cells independent of MTOR and HIF1A signaling. Autophagy. 2016:12:1631-46.

21. Park CW, Hong SM, Kim ES, Kwon JH, Kim KT, Nam HG, Choi KY. BNIP3 is degraded by ULK1-dependent autophagy via MTORC1 and AMPK. Autophagy. 2013;9:345-60.

22. Egan DF, Shackelford DB, Mihaylova MM, Gelino S, Kohnz RA, Mair W, Vasquez DS, Joshi A, Gwinn DM, Taylor R, et al. Phosphorylation of ULK1 (hATG1) by AMP-activated protein kinase connects energy sensing to mitophagy. Science. 2011;331:456-61.
23. Adi-Harel S, Erlich S, Schmukler E, Cohen-Kedar S, Segev O, Mizrachy L, Hirsch JA, Pinkas-Kramarski R. Beclin 1 self-association is independent of autophagy induction by amino acid deprivation and rapamycin treatment. J Cell Biochem. 2010;110:1262-71.

24. Shi CS, Kehrl JH. TRAF6 and A20 regulate lysine 63-linked ubiquitination of Beclin-1 to control TLR4-induced autophagy. Sci Signal. 2010;3:ra42.

25. Zou ZZ, Yuan ZY, Zhang QX, Long ZJ, Chen JN, Tang ZP, Zhu YL, Chen SP, Xu J, Yan M, et al. Aurora kinase A inhibition-induced autophagy triggers drug resistance in breast cancer cells. Autophagy. 2012;8:1798-810.

26. Wei YJ, Pattingre S, Sinha S, Bassik M, Levine B. JNK1-mediated phosphorylation of $\mathrm{BCl}-2$ regulates starvation-induced autophagy. Mol Cell. 2008;30:678-88.

27. Li H, Wang P, Sun QH, Ding WX, Yin XM, Sobol RW, Stolz DB, Yu J, Zhang $\mathrm{L}$. Following cytochrome $c$ release, autophagy is inhibited during chemotherapy-induced apoptosis by Caspase 8-mediated cleavage of Beclin 1. Cancer Res. 2011;71:3625-34.

28. Wirawan E, Vande Walle L, Kersse K, Cornelis S, Claerhout S, Vanoverberghe I, Roelandt R, De Rycke R, Verspurten J, Declercq W, et al. Caspase-mediated cleavage of Beclin-1 inactivates Beclin-1-induced autophagy and enhances apoptosis by promoting the release of proapoptotic factors from mitochondria. Cell Death Dis. 2010;1:e18.

29. Broz DK, Mello SS, Bieging KT, Jiang DD, Dusek RL, Brady CA, Sidow A, Attardi LD. Global genomic profiling reveals an extensive p53-regulated autophagy program contributing to key p53 responses. Gene Dev. 2013;27:1016-31.

30. Feng ZH, Hu WW, de Stanchina E, Teresky AK, Jin SK, Lowe S, Levine AJ. The regulation of AMPK beta 1, TSC2, and PTEN expression by p53: Stress, cell and tissue specificity, and the role of these gene products in modulating the IGF-1-AKT-mTOR pathways. Cancer Res. 2007:67:3043-53.

31. Kim BR, Jeong YA, Kim DY, Kim JL, Jeong S, Na YJ, Yun HK, Park SH, Jo ML, Ashktorab H, et al. Genipin increases oxaliplatin-induced cell death through autophagy in gastric cancer. J Cancer. 2020;11:460-7.

32. Napoli M, Flores ER. The family that eats together stays together: new p53 family transcriptional targets in autophagy. Gene Dev. 2013;27:971-4.

33. Huang YP, Guerrero-Preston R, Ratovitski EA. Phospho-Delta Np63 alpha-dependent regulation of autophagic signaling through transcription and micro-RNA modulation. Cell Cycle. 2012;11:1247-59.

34. Rosenbluth JM, Mays DJ, Pino MF, Tang LJ, Pietenpol JA. A gene signature-based approach identifies $\mathrm{MTOR}$ as a regulator of $\mathrm{p} 73$. Mol Cell Biol. 2008;28:5951-64.

35. He Z, Liu H, Agostini M, Yousefi S, Perren A, Tschan MP, MakTW, Melino G, Simon HU. p73 regulates autophagy and hepatocellular lipid metabolism through a transcriptional activation of the ATG5 gene. Cell Death Differ. 2013:20:1415-24.

36. Tasdemir E, Maiuri MC, Galluzzi L, Vitale I, Djavaheri-Mergny M, D’Amelio M, Criollo A, Morselli E, Zhu C, Harper F, et al. Regulation of autophagy by cytoplasmic p53. Nat Cell Biol. 2008;10:676-87.

37. Mehrbod P, Ande SR, Alizadeh J, Rahimizadeh S, Shariati A, Malek H, Hashemi M, Glover KKM, Sher AA, Coombs KM, et al. The roles of apoptosis, autophagy and unfolded protein response in arbovirus, influenza virus, and HIV infections. Virulence. 2019;10:376-413.

38. Kim EM, Jung CH, Kim J, Hwang SG, Park JK, Um HD. The p53/p21 complex regulates cancer cell invasion and apoptosis by targeting $\mathrm{BCl}-2$ family proteins. Cancer Res. 2017;77:3092-100.

39. Morselli E, Tasdemir E, Maiuri MC, Galluzzi L, Kepp O, Criollo A, Vicencio JM, Soussi T, Kroemer G. Mutant p53 protein localized in the cytoplasm inhibits autophagy. Cell Cycle. 2008;7:3056-61.

40. Cordani M, Oppici E, Dando I, Butturini E, Dalla Pozza E, Nadal-Serrano M, Oliver J, Roca P, Mariotto S, Cellini B, et al. Mutant p53 proteins counteract autophagic mechanism sensitizing cancer cells to mTOR inhibition. Mol Oncol. 2016:10:1008-29.

41. Dando I, Cordani M, Donadelli M. Mutant p53 and mTOR/PKM2 regulation in cancer cells. IUBMB Life. 2016:68:722-6.

42. Khromova NV, Kopnin PB, Stepanova EV, Agapova LS, Kopnin BP. p53 hot-spot mutants increase tumor vascularization via ROS-mediated activation of the HIF1NEGF-A pathway. Cancer Lett. 2009;276:143-51.

43. Valenti F, Ganci F, Fontemaggi G, Sacconi A, Strano S, Blandino G, Di Agostino S. Gain of function mutant p53 proteins cooperate with E2F4 
to transcriptionally downregulate RAD17 and BRCA1 gene expression. Oncotarget. 2015;6:5547-66.

44. Rodriguez OC, Choudhury S, Kolukula V, Vietsch EE, Catania J, Preet A, Reynoso K, Bargonetti J, Wellstein A, Albanese C, et al. Dietary downregulation of mutant p53 levels via glucose restriction: mechanisms and implications for tumor therapy. Cell Cycle. 2012;11:4436-46.

45. Sun XX, Challagundla KB, Dai MS. Positive regulation of p53 stability and activity by the deubiquitinating enzyme Otubain 1. EMBO J. 2012:31:576-92.

46. Cicenas J, Zalyte E, Rimkus A, Dapkus D, Noreika R, Urbonavicius S. JNK, p38, ERK, and SGK1 inhibitors in cancer. Cancers. 2018;10:1.

47. Tu QQ, Zheng RY, Li J, Hu L, Chang YX, Li L, Li MH, Wang RY, Huang DD, Wu MC, et al. Palmitic acid induces autophagy in hepatocytes via JNK2 activation. Acta Pharmacol Sin. 2014;35:504-12.

48. Zhang Q, Kuang H, Chen C, Yan J, Do-Umehara HC, Liu XY, Dada L, Ridge KM, Chandel NS, Liu J. The kinase Jnk2 promotes stress-induced mitophagy by targeting the small mitochondrial form of the tumor suppressor ARF for degradation. Nat Immunol. 2015;16:458-66.

49. Xu P, Das M, Reilly J, Davis RJ. JNK regulates FoxO-dependent autophagy in neurons. Genes Dev. 2011;25:310-22.

50. Zhou YY, LiY, Jiang WQ, Zhou LF. MAPK/JNK signalling: a potential autophagy regulation pathway. Biosci Rep. 2015;35:e00199.

51. Lavallard VJ, Meijer AJ, Codogno P, Gual P. Autophagy, signaling and obesity. Pharmacol Res. 2012;66:513-25.

52. Fitzwalter BE, Thorburn A. FOXO3 links autophagy to apoptosis. Autophagy. 2018;14:1467-8

53. Wang N, Zimmerman K, Raab RW, McKown RL, Hutnik CML, Talla V, Tyler MF, Lee JK, Laurie GW. Lacritin rescues stressed epithelia via rapid Forkhead Box O3 (FOXO3)-associated autophagy that restores metabolism. J Biol Chem. 2013;288:18146-61.

54. Matsuzawa T, Kim BH, Shenoy AR, Kamitani S, Miyake M, MacMicking JD. IFN-gamma elicits macrophage autophagy via the p38 MAPK signaling pathway. J Immunol. 2012;189:813-8.

55. McClung JM, Judge AR, Powers SK, Yan Z. p38 MAPK links oxidative stress to autophagy-related gene expression in cachectic muscle wasting. Am J Physiol Cell Physiol. 2010;298:C542-9.

56. Keil E, Hocker R, Schuster M, Essmann F, Ueffing N, Hoffman B, Liebermann DA, Pfeffer K, Schulze-Osthoff K, Schmitz I. Phosphorylation of Atg 5 by the Gadd45 beta-MEKK4-p38 pathway inhibits autophagy. Cell Death Differ. 2013;20:321-32.

57. Henson SM, Lanna A, Riddell NE, Franzese O, Macaulay R, Griffiths SJ, Puleston DJ, Watson AS, Simon AK, Tooze SA, et al. p38 signaling inhibits mTORC1-independent autophagy in senescent human CD8(+) T cells. J Clin Invest. 2014:124:4004-16.

58. Settembre C, Di Malta C, Polito VA, Garcia-Arencibia M, Vetrini F, Erdin S, Erdin SU, Huynh T, Medina D, Colella P, et al. TFEB links autophagy to lysosomal biogenesis. Science. 2011;332:1429-33.

59. Colecchia D, Strambi A, Sanzone S, lavarone C, Rossi M, Dall'Armi C, Piccioni F, di Pianella AV, Chiariello M. MAPK15/ERK8 stimulates autophagy by interacting with LC3 and GABARAP proteins. Autophagy. 2012:8:1724-40.

60. Kinsey CG, Camolotto SA, Boespflug AM, Gullien KP, Foth M, Shea JE, Seipp MT, Yap JT, Burrell LD, Lum DH, et al. Protective autophagy elicited by RAF $\rightarrow$ MEK $\rightarrow$ ERK inhibition suggests a treatment strategy for RASdriven cancers. Nat Med. 2019;25:620-7.

61. Bryant KL, Stalnecker CA, Zeitouni D, Klomp JE, Peng S, Tikunov AP, Gunda V, Pierobon M, Waters AM, George SD, et al. Combination of ERK and autophagy inhibition as a treatment approach for pancreatic cancer. Nat Med. 2019;25:628-40.

62. Zhang JX, Liang Y, Lin YB, Liu YB, You Y, Yin WQ. IRE1 alpha-TRAF2-ASK1 pathway is involved in CSTMP-induced apoptosis and ER stress in human non-small cell lung cancer A549 cells. Biomed Pharmacother. 2016;82:281-9.

63. Kang MJ, Chung J, Ryoo HD. CDK5 and MEKK1 mediate pro-apoptotic signalling following endoplasmic reticulum stress in an autosomal dominant retinitis pigmentosa model. Nat Cell Biol. 2012:4:409-15.

64. Selimovic D, Porzig BBOW, El-Khattouti A, Badura HE, Ahmad M, Ghanjati F, Santourlidis S, Haikel Y, Hassan M. Bortezomib/proteasome inhibitor triggers both apoptosis and autophagy-dependent pathways in melanoma cells. Cell Signal. 2013:25:308-18.
65. Vidal RL, Figueroa A, Court FA, Thielen P, Molina C, Wirth C, Caballero B, Kiffin $R$, Segura-Aguilar J, Cuervo AM, et al. Targeting the UPR transcription factor XBP1 protects against Huntington's disease through the regulation of FoxO1 and autophagy. Hum Mol Genet. 2012;21:2245-62.

66. Zhou YJ, Lee J, Reno CM, Sun C, Park SW, Chung J, Lee J, Fisher SJ, White $\mathrm{MF}$, Biddinger $\mathrm{SB}$, et al. Regulation of glucose homeostasis through a XBP-1-FoxO1 interaction. Nat Med. 2011:17:356-61.

67. Gade P, Ramachandran G, Maachani UB, Rizzo MA, Okada T, Prywes R, Cross AS, Mori K, Kalvakolanu DV. An IFN-gamma-stimulated ATF6-C/ EBP-beta-signaling pathway critical for the expression of death associated protein kinase 1 and induction of autophagy. Proc Natl Acad Sci U S A. 2012;109:10316-21.

68. Zhou Y, Zhang S, Dai CS, Tang SS, Yang XY, Li DW, Zhao KN, Xiao XL. Quinocetone triggered ER stress-induced autophagy via ATF6/DAPK1modulated mAtg9a trafficking. Cell Biol Toxicol. 2016;32:141-52.

69. Wang J, Kang RY, Huang H, Xi XY, Wang B, Wang JW, Zhao ZD. Hepatitis C virus core protein activates autophagy through EIF2AK3 and ATF6 UPR pathway-mediated MAP1LC3B and ATG12 expression. Autophagy. 2014;10:766-84

70. Tian H, Li YY, Kang PP, Wang ZC, Yue F, Jiao P, Yang NN, Qin SC, Yao ST. Endoplasmic reticulum stress-dependent autophagy inhibits glycated high-density lipoprotein-induced macrophage apoptosis by inhibiting CHOP pathway. J Cell Mol Med. 2019;23:2954-69.

71. Bchir W, Maurin AC, Carraro V, Averous J, Jousse C, Muranishi Y, Parry L, Stepien G, Fafournoux P, Bruhat A. The elF2 alpha/ATF4 pathway is essential for stress-induced autophagy gene expression. Nucleic Acids Res. 2013:41:7683-99.

72. Matsumoto H, Miyazaki S, Matsuyama S, Takeda M, Kawano M, Nakagawa H, Nishimura K, Matsuo S. Selection of autophagy or apoptosis in cells exposed to ER-stress depends on ATF4 expression pattern with or without CHOP expression. Biol Open. 2013;2:1084-90.

73. Zhou Y, Liang XY, Chang H, Shu FR, Wu Y, Zhang T, Fu YJ, Zhang QY, Zhu JD, Mi MT. Ampelopsin-induced autophagy protects breast cancer cells from apoptosis through Akt-mTOR pathway via endoplasmic reticulum stress. Cancer Sci. 2014;105:1279-87.

74. Rodriguez-Hernandez MA, Gonzalez R, de la Rosa AJ, Gallego P, Ordonez R, Navarro-Villaran E, Contreras L, Rodriguez-Arribas M Gonzalez-Gallego J, Alamo-Martinez JM, et al. Molecular characterization of autophagic and apoptotic signaling induced by sorafenib in liver cancer cells. J Cell Physiol. 2019;234:692-708.

75. Crawford SE, Estes MK. Viroporin-mediated calcium-activated autophagy. Autophagy. 2013:9:797-8.

76. Gonnella R, Granato M, Farina A, Santarelli R, Faggioni A, Cirone M. PKC theta and p38 MAPK activate the EBV lytic cycle through autophagy induction. BBA-Mol Cell Res. 2015;1853:1586-95.

77. Bellot G, Garcia-Medina R, Gounon P, Chiche J, Roux D, Pouyssegur J, Mazure NM. Hypoxia-induced autophagy is mediated through hypoxiainducible factor induction of BNIP3 and BNIP3L via their BH3 domains. Mol Cell Biol. 2009:29:2570-81.

78. Sassone F, Margulets V, Maraschi A, Rodighiero S, Passafaro M, Silani V, Ciammola A, Kirshenbaum LA, Sassone J. Bcl-2/adenovirus E1B 19-kDa interacting protein (BNip3) has a key role in the mitochondrial dysfunction induced by mutant huntingtin. Hum Mol Genet. 2015:24:6530-9.

79. Niu C, Chen ZW, Kim KT, Sun J, Xue M, Chen G, Li ST, Shen YJ, Zhu ZX, Wang $X$, et al. Metformin alleviates hyperglycemia-induced endothelial impairment by downregulating autophagy via the Hedgehog pathway. Autophagy. 2019;15:843-70

80. Papandreou I, Lim AL, Laderoute K, Denko NC. Hypoxia signals autophagy in tumor cells via AMPK activity, independent of HIF-1, BNIP3, and BNIP3L. Cell Death Differ. 2008;15:1572-81.

81. Rouschop KMA, van den Beucken T, Dubois L, Niessen H, Bussink J, Savelkouls K, Keulers T, Mujcic H, Landuyt W, Voncken JW, et al. The unfolded protein response protects human tumor cells during hypoxia through regulation of the autophagy genes MAP1LC3B and ATG5. J Clin Invest. 2010;120:127-41.

82. Poillet-Perez L, Despouy G, Delage-Mourroux R, Boyer-Guittaut M. Interplay between ROS and autophagy in cancer cells, from tumor initiation to cancer therapy. Redox Biol. 2015;4:184-92.

83. Zhang XL, Cheng XP, Yu L, Yang JS, Calvo R, Patnaik S, Hu X, Gao Q Yang MM, Lawas M, et al. MCOLN1 is a ROS sensor in lysosomes that regulates autophagy. Nat Commun. 2016;7:12109. 
84. Sinha RA, Singh BK, Zhou J, Wu YJ, Farah BL, Ohba K, Lesmana R, Gooding J, Bay BH, Yen PM. Thyroid hormone induction of mitochondrial activity is coupled to mitophagy via ROS-AMPK-ULK1 signaling. Autophagy. 2015;11:1341-57.

85. Datta S, Chakraborty S, Panja C, Ghosh S. Reactive nitrogen species control apoptosis and autophagy in K562 cells: implication of TAp73 alpha, induction in controlling autophagy. Free Radical Res. 2018;52:491-506.

86. Kubota M, Kakimoto K, Nakagawa T, Koubayashi E, Nakazawa K, Tawa H, Hirata Y, Okada T, Kawakami K, Asai A, et al. Autophagy deficiency exacerbates colitis through excessive oxidative stress and MAPK signaling pathway activation. PLoS ONE. 2019;14:e0225066.

87. Hu LL, Wang H, Huang L, Zhao Y, Wang JJ. Crosstalk between autophagy and intracellular radiation response. Int J Oncol. 2016;49:2217-26.

88. Kaminskyy VO, Zhivotovsky B. Free radicals in cross talk between autophagy and apoptosis. Antioxid Redox Sign. 2014;21:86-102.

89. Tschan MP, Jost M, Batliner J, Fey MF. The antophagy gene ULK1 plays a role in AML differentiation and is negatively regulated by the oncogenic microRNA 106a. Blood. 2010;116:223-223.

90. Huang YP, Chuang AY, Ratovitski EA. Phospho-Delta Np63 alpha/miR885-3p axis in tumor cell life and cell death upon cisplatin exposure. Cell Cycle. 2011;10:3938-47.

91. Zou ZY, Wu LP, Ding HY, Wang Y, Zhang YQ, Chen XJ, Chen X, Zhang $C Y$, Zhang QP, Zen K. MicroRNA-30a sensitizes tumor cells to cisplatinum via suppressing Beclin 1-mediated autophagy. J Biol Chem. 2012;287:4148-56.

92. Korkmaz G, le Sage C, Tekirdag KA, Agami R, Gozuacik D. miR-376b controls starvation and mTOR inhibition-related autophagy by targeting ATG4C and BECN1. Autophagy. 2012;8:165-76.

93. Yu Y, Yang L, Zhao M, Zhu S, Kang R, Vernon P, Tang D, Cao L. Targeting microRNA-30a-mediated autophagy enhances imatinib activity against human chronic myeloid leukemia cells. Leukemia. 2012;26:1752-60.

94. Frankel LB, Wen JY, Lees M, Hoyer-Hansen M, Farkas T, Krogh A, Jaattela $M$, Lund AH. microRNA-101 is a potent inhibitor of autophagy. EMBO J. 2011;30:4628-41.

95. Mikhaylova O, Stratton Y, Hall D, Kellner E, Ehmer B, Drew AF, Gallo CA, Plas DR, Biesiada J, Meller J, et al. VHL-regulated miR-204 suppresses tumor growth through inhibition of LC3B-mediated autophagy in renal clear cell carcinoma. Cancer Cell. 2012;21:532-46.

96. Meenhuis A, van Veelen PA, de Looper H, van Boxtel N, van den Berge IJ, Sun SM, Taskesen E, Stern P, de Ru AH, van Adrichem AJ, et al. MiR17/20/93/106 promote hematopoietic cell expansion by targeting sequestosome 1-regulated pathways in mice. Blood. 2011;118:916-25.

97. Yeh LY, Liu CJ, Wong YK, Chang C, Lin SC, Chang KW. miR-372 inhibits p62 in head and neck squamous cell carcinoma in vitro and in vivo. Oncotarget. 2015;6:6062-75.

98. Zhang E, Wang J, Chu JJ, Yang C, Xiao H, Zhao CL, Sun ZW, Gao X, Chen GH, Han ZT, et al. MicroRNA-146a induced by hypoxia promotes chondrocyte autophagy through Bcl-2. Cell Physiol Biochem. 2015;37:1442-53.

99. Chen S, Wu J, Jiao K, Wu Q, Ma JJ, Chen D, Kang JQ, Zhao GD, Shi YQ, Fan DM, et al. MicroRNA-495-3p inhibits multidrug resistance by modulating autophagy through GRP78/mTOR axis in gastric cancer. Cell Death Dis. 2018:9:1070.

100. Han WD, Fu XH, Xie JS, Meng ZP, Gu Y, Wang XC, Li L, Pan HM, Huang WD. miR-26a enhances autophagy to protect against ethanol-induced acute liver injury. J Mol Med. 2015;93:1045-55.

101. Tazawa H, Yano S, Yoshida R, Yamasaki Y, Sasaki T, Hashimoto Y, Kuroda S, Ouchi M, Onishi T, Uno F, et al. Genetically engineered oncolytic adenovirus induces autophagic cell death through an E2F1-microRNA-7-epidermal growth factor receptor axis. Int J Cancer. 2012;131:2939-50.

102. Zhai H, Song B, Xu X, Zhu W, Ju J. Inhibition of autophagy and tumor growth in colon cancer by miR-502. Oncogene. 2013;32:1570-9.

103. Li GP, Qian L, Tang XQ, Chen Y, Zhao ZY, Zhang CW. Long non-coding RNA growth arrest-specific 5 (GAS5) acts as a tumor suppressor by promoting autophagy in breast cancer. Mol Med Rep. 2020;22:2460-8.

104. Li P, He J, Yang Z, Ge SF, Zhang H, Zhong Q, Fan XQ. ZNNT1 long noncoding RNA induces autophagy to inhibit tumorigenesis of uveal melanoma by regulating key autophagy gene expression. Autophagy. 2020;16:1186-99.

105. Li XY, Zhou Y, Yang L, Ma YB, Peng XQ, Yang S, Li HY, Liu JG. LncRNA NEAT1 promotes autophagy via regulating miR-204/ATG3 and enhanced cell resistance to sorafenib in hepatocellular carcinoma. J Cell Physiol. 2020;235:3402-13.

106. Liu F, Ai FY, Zhang DC, Tian L, Yang ZY, Liu SJ. LncRNA NEAT1 knockdown attenuates autophagy to elevate 5-FU sensitivity in colorectal cancer via targeting miR-34a. Cancer Med. 2020;9:1079-91.

107. Wang J, Xie SD, Yang JJ, Xiong HC, Jia YL, Zhou YL, Chen YX, Ying XG, Chen $\mathrm{C}$, Ye $\mathrm{CY}$, et al. The long noncoding RNA H19 promotes tamoxifen resistance in breast cancer via autophagy. J Hematol Oncol. 2019;12:81.

108. Zhou CF, Yi CH, Yi YX, Qin WY, Yan YN, Dong XY, Zhang XW, Huang Y, Zhang $R$, Wei J, et al. LncRNA PVT1 promotes gemcitabine resistance of pancreatic cancer via activating Wnt/beta-catenin and autophagy pathway through modulating the miR-619-5p/Pygo2 and miR-619-5p/ ATG14 axes. Mol Cancer. 2020;19:118.

109. Yang YX, Chen D, Liu H, Yang K. Increased expression of IncRNA CASC9 promotes tumor progression by suppressing autophagy-mediated cell apoptosis via the AKT/mTOR pathway in oral squamous cell carcinoma. Cell Death Dis. 2019;10:41.

110. Su YY, Yao SW, Zhao S, Li JC, Li HY. LncRNA CCAT1 functions as apoptosis inhibitor in podocytes via autophagy inhibition. J Cell Biochem. 2020;121:621-31.

111. Liu CH, Zhang Y, She XL, Fan L, Li PY, Feng JB, Fu HJ, Liu Q, Liu Q, Zhao $\mathrm{CH}$, et al. A cytoplasmic long noncoding RNA LINC00470 as a new AKT activator to mediate glioblastoma cell autophagy. J Hematol Oncol. 2018;11:77.

112. Wang C, Tan CL, Wen Y, Zhang DZ, Li GF, Chang L, Su J, Wang X. FOXP1induced InCRNA CLRN1-AS1 acts as a tumor suppressor in pituitary prolactinoma by repressing the autophagy via inactivating Wnt/betacatenin signaling pathway. Cell Death Dis. 2019;10:499.

113. Pu ZJ, Wu LF, Guo YT, Li GP, Xiang MQ, Liu LX, Zhan HL, Zhou XT, Tan H. LncRNA MEG3 contributes to adenosine-induced cytotoxicity in hepatoma HepG2 cells by downregulated ILF3 and autophagy inhibition via regulation PI3K-AKT-mTOR and beclin-1 signaling pathway. J Cell Biochem. 2019;120:18172-85.

114. White E. Autophagy and p53. Cold Spring Harb Perspect Med. 2016:6:a026120.

115. Yoon JH, Ahn SG, Lee BH, Jung SH, Oh SH. Role of autophagy in chemoresistance: regulation of the ATM-mediated DNA-damage signaling pathway through activation of DNA-PKcs and PARP-1. Biochem Pharmacol. 2012;83:747-57.

116. Anand SK, Sharma A, Singh N, Kakkar P. Entrenching role of cell cycle checkpoints and autophagy for maintenance of genomic integrity. DNA Repair. 2020;86:102748.

117. Zhang LH, Yang AJ, Wang M, Liu W, Wang CY, Xie XF, Chen X, Dong JF, Li M. Enhanced autophagy reveals vulnerability of P-gp mediated epirubicin resistance in triple negative breast cancer cells. Apoptosis. 2016:21:473-88.

118. Lim SC, Hahm KS, Lee SH, Oh SH. Autophagy involvement in cadmium resistance through induction of multidrug resistance-associated protein and counterbalance of endoplasmic reticulum stress WI38 lung epithelial fibroblast cells. Toxicology. 2010;276:18-26.

119. Wu W, Schecker J, Wurstle S, Schneider F, Schonfelder M, Schlegel J. Aldehyde dehydrogenase 1A3 (ALDH1A3) is regulated by autophagy in human glioblastoma cells. Cancer Lett. 2018:417:112-23.

120. Zhang CY, Hu JW, Wang WS, Sun Y, Sun K. HMGB1-induced aberrant autophagy contributes to insulin resistance in granulosa cells in PCOS. FASEB J. 2020;34:9563-74.

121. Cicco S, Cicco G, Racanelli V, Vacca A. Neutrophil extracellular traps (NETs) and damage-associated molecular patterns (DAMPs): two potential targets for COVID-19 treatment. Mediators Inflamm. 2020;2020:7527953.

122. Li SY, Wei YL. Association of HMGB1, BRCA1 and P62 expression in ovarian cancer and chemotherapy sensitivity. Oncol Lett. 2018;15:9572-6.

123. Huang CY, Chiang SF, Chen WTL, Ke TW, Chen TW, You YS, Lin CY, Chao KSC. HMGB1 promotes ERK-mediated mitochondrial Drp1 phosphorylation for chemoresistance through RAGE in colorectal cancer. Cell Death Dis. 2018:9:1004.

124. Zheng $H$, Chen JN, Yu X, Jiang P, Yuan L, Shen HS, Zhao LH, Chen PF, Yang M. HMGB1 enhances drug resistance and promotes in vivo tumor growth of lung cancer cells. DNA Cell Biol. 2016;35:622-7. 
125. Hou W, Han J, Lu CS, Goldstein LA, Rabinowich H. Autophagic degradation of active caspase-8: a crosstalk mechanism between autophagy and apoptosis. Autophagy. 2010;6:891-900.

126. Yang P, Song RR, Li N, Sun K, Shi F, Liu HL, Shen FH, Jiang SF, Zhang L, Jin YL. Silica dust exposure induces autophagy in alveolar macrophages through switching Beclin1 affinity from BCl-2 to PIK3C3. Environ Toxicol. 2020;35:758-67.

127. Zhu JL, Cai YS, Xu K, Ren XY, Sun J, Lu SM, Chen JH, Xu P. Beclin1 overexpression suppresses tumor cell proliferation and survival via an autophagy-dependent pathway in human synovial sarcoma cells. Oncol Rep. 2018;40:1927-36.

128. Moon HS, Kim B, Gwak H, Suh DH, Song YS. Autophagy and protein kinase RNA-like endoplasmic reticulum kinase (PERK)/eukaryotic initiation factor 2 alpha kinase (elF2 alpha) pathway protect ovarian cancer cells from metformin-induced apoptosis. Mol Carcinog. 2016:55:346-56.

129. Elgendy M, Sheridan C, Brumatti G, Martin SJ. Oncogenic Rasinduced expression of Noxa and Beclin-1 promotes autophagic cell death and limits clonogenic survival. Mol Cell. 2011;42:23-35.

130. Zareba I, Huynh TYL, Kazberuk A, Teu J, Klupczynska A, Matysiak J, Surazynski A, Palkaa J. Overexpression of prolidase induces autophagic death in MCF-7 breast cancer cells. Cell Physiol Biochem. 2020;54:875-87.

131. Lamy L, Ngo VN, Emre NCT, Shaffer AL, Yang YD, Tian EM, Nair V, Kruhlak MJ, Zingone A, Landgren O, et al. Control of autophagic cell death by Caspase-10 in multiple myeloma. Cancer Cell. 2013;23:435-49.

132. Zeng $X$, Zhao H, Li YB, Fan JJ, Sun Y, Wang SF, Wang ZY, Song P, Ju DW. Targeting Hedgehog signaling pathway and autophagy overcomes drug resistance of BCR-ABL-positive chronic myeloid leukemia. Autophagy. 2015;11:355-72.

133. Fan QW, Cheng C, Hackett C, Feldman M, Houseman BT, Nicolaides T, Haas-Kogan D, James CD, Oakes SA, Debnath J, et al. Akt and autophagy cooperate to promote survival of drug-resistant glioma. Sci Signal. 2010;3:ra81.

134. Chang ZX, Shi G, Jin JQ, Guo HT, Guo XF, Luo FY, Song YG, Jia XJ. Dual PI3K/mTOR inhibitor NVP-BEZ235-induced apoptosis of hepatocellular carcinoma cell lines is enhanced by inhibitors of autophagy. Int J Mol Med. 2013:31:1449-56.

135. Janku F, McConkey DJ, Hong DS, Kurzrock R. Autophagy as a target for anticancer therapy. Nat Rev Clin Oncol. 2011:8:528-39.

136. Bellodi C, Lidonnici MR, Hamilton A, Helgason GV, Soliera AR, Ronchetti M, Galavotti S, Young KW, Selmi T, Yacobi R, et al. Targeting autophagy potentiates tyrosine kinase inhibitor-induced cell death in Philadelphia chromosome-positive cells, including primary CML stem cells. J Clin Invest. 2009;1 19:1109-23.

137. Sun SY. Enhancing perifosine's anticancer efficacy by preventing autophagy. Autophagy. 2010;6:184-5

138. Rangwala R, Chang YYC, Hu J, Algazy K, Evans T, Fecher L, Schuchter L, Torigian DA, Panosian J, Troxel A, et al. Combined mTOR and autophagy inhibition Phase I trial of hydroxychloroquine and temsirolimus in patients with advanced solid tumors and melanoma. Autophagy. 2014;10:1391-402.

139. Zhu K, Dunner K, McConkey DJ. Proteasome inhibitors activate autophagy as a cytoprotective response in human prostate cancer cells. Oncogene. 2010;29:451-62.

140. Zang Y, Thomas SM, Chan ET, Kirk CJ, Freilino ML, DeLancey HM, Grandis JR, Li CY, Johnson DE. The next generation proteasome inhibitors carfilzomib and oprozomib activate prosurvival autophagy via induction of the unfolded protein response and ATF4. Autophagy. 2012;8:1873-4

141. Carew JS, Medina EC, Esquivel JA, Mahalingam D, Swords R, Kelly K, Zhang H, Huang P, Mita AC, Mita MM, et al. Autophagy inhibition enhances vorinostat-induced apoptosis via ubiquitinated protein accumulation. J Cell Mol Med. 2010;14:2448-59.

142. Srivastav AK, Dubey D, Chopra D, Singh J, Negi S, Mujtaba SF, Dwivedi A, Ray RS. Oxidative stress-mediated photoactivation of carbazole inhibits human skin cell physiology. J Cell Biochem. 2020;121:1273-82.

143. Chen HY, Huang TC, Shieh TM, Wu CH, Lin LC, Hsia SM. Isoliquiritigenin induces autophagy and inhibits ovarian cancer cell growth. Int J Mol Sci. 2017;18:2025
144. Jahanafrooz Z Motamed N, Rinner B, Mokhtarzadeh A, Baradaran B. Silibinin to improve cancer therapeutic, as an apoptotic inducer, autophagy modulator, cell cycle inhibitor, and microRNAs regulator. Life Sci. 2018;213:236-47.

145. Kauntz H, Bousserouel S, Gosse F, Raul F. Silibinin triggers apoptotic signaling pathways and autophagic survival response in human colon adenocarcinoma cells and their derived metastatic cells. Apoptosis. $2011 ; 16: 1042-53$

146. Zhan ZZ, Li Q, Wu P, Ye Y, Tseng HY, Zhang LJ, Zhang XD. Autophagymediated HMGB1 release antagonizes apoptosis of gastric cancer cells induced by vincristine via transcriptional regulation of Mcl-1. Autophagy. 2012;8:109-21.

147. Li XQ, Fan Z. The epidermal growth factor receptor antibody cetuximab induces autophagy in cancer cells by downregulating HIF-1 alpha and Bcl-2 and activating the Beclin 1/hVps34 complex. Cancer Res. 2010;70:5942-52.

148. Cufi S, Vazquez-Martin A, Oliveras-Ferraros C, Corominas-Faja B, Cuyas E, Lopez-Bonet E, Martin-Castillo B, Joven J, Menendez JA. The anti-malarial chloroquine overcomes primary resistance and restores sensitivity to Trastuzumab in HER2-positive breast cancer. Sci Rep. 2013:3:2469.

149. Luca T, Barresi V, Privitera G, Musso N, Caruso M, Condorelli DF, Castorina S. In vitro combined treatment with cetuximab and trastuzumab inhibits growth of colon cancer cells. Cell Prolif. 2014;47:435-47.

150. Al-Batran SE, Moorahrend E, Maintz C, Goetze TO, Hempel D, ThussPatience P, Gaillard VE, Hegewisch-Becker S. Clinical practice observation of Trastuzumab in patients with human epidermal growth receptor 2-positive metastatic adenocarcinoma of the stomach or gastroesophageal junction. Oncologist. 2020;25:e1181-7.

151. Wang YC, Zhang XY, Fan JJ, Chen W, Luan JY, Nan YY, Wang SF, Chen QC, Zhang YJ, Wu YL, et al. Activating autophagy enhanced the antitumor effect of antibody drug conjugates Rituximab-monomethyl auristatin E. Front Immunol. 2018;9:1799.

152. Guo XL, Li D, Sun K, Wang J, Liu Y, Song JR, Zhao QD, Zhang SS, Deng WJ, Zhao X, et al. Inhibition of autophagy enhances anticancer effects of bevacizumab in hepatocarcinoma. J Mol Med. 2013;91:473-83.

153. Maimaitili Y, Inase A, Miyata Y, Kitao A, Mizutani Y, Kakiuchi S, Shimono $Y$, Saito Y, Sonoki T, Minami H, et al. An mTORC1/2 kinase inhibitor enhances the cytotoxicity of gemtuzumab ozogamicin by activation of Iysosomal function. Leukemia Res. 2018;74:68-74.

154. Mizutani Y, Inase A, Maimaitili Y, Miyata Y, Kitao A, Matsumoto $H_{1}$ Kawaguchi K, Higashime A, Goto H, Kurata K, et al. An mTORC1/2 dual inhibitor, AZD2014, acts as a lysosomal function activator and enhances gemtuzumab ozogamicin-induced apoptosis in primary human leukemia cells. Int J Hematol. 2019;1 10:490-9.

155. Gallo S, Gatti S, Sala V, Albano R, Costelli P, Casanova E, Comoglio PM, Crepaldi T. Agonist antibodies activating the Met receptor protect cardiomyoblasts from cobalt chloride-induced apoptosis and autophagy. Cell Death Dis. 2014;5:e1 185.

156. Alinari L, Baiocchi RA, Praetorius-lbba M. FTY720-induced blockage of autophagy enhances anticancer efficacy of milatuzumab in mantle cell lymphoma: Is FTY720 the next autophagy-blocking agent in lymphoma treatment? Autophagy. 2012;8:416-7.

157. Illidge T, Ivanov A, Beers SA, Walshe C, Chan C, Alduaij W, Glennie MJ, Cragg MS. Novel mechanisms of non-apoptotic cell death evoked by type II anti-CD20 (Tositumomab) and HLA-DR monoclonal antibodies. Blood. 2008;112:326-326

158. Xu W, Song F, Wang B, Li KS, Tian M, Yu M, Pan XR, Shi BZ, Liu JW, Gu JR, et al. The effect of and mechanism underlying autophagy in hepatocellular carcinoma induced by $\mathrm{CH} 12$, a monoclonal antibody directed against epidermal growth factor receptor variant III. Cell Physiol Biochem. 2018;46:226-37.

159. Zhang MJ, He J, Liu ZQ, Lu Y, Zheng YH, Li HY, Xu JD, Liu H, Qian JF, Orlowski RZ, et al. Anti-beta(2)-microglobulin monoclonal antibodies overcome bortezomib resistance in multiple myeloma by inhibiting autophagy. Oncotarget. 2015;6:8567-78.

160. Booth L, Roberts JL, Poklepovic A, Dent P. [pemetrexed plus sildenafil], via autophagy-dependent HDAC downregulation, enhances the immunotherapy response of NSCLC cells. Cancer Biol Ther. 2017;18:705-14.

161. Hu YR, Yu YC, You SW, Li KQ, Tong XC, Chen SR, Chen ED, Lin XZ, Chen YF. Long noncoding RNA MALAT1 regulates autophagy associated 
chemoresistance via miR-23b-3p sequestration in gastric cancer. Mol cancer. 2017;16:174.

162. Huang LM, Hu CQ, Cao H, Wu XL, Wang RP, Lu H, Li H, Chen H. MicroRNA-29c increases the chemosensitivity of pancreatic cancer cells by inhibiting USP22 mediated autophagy. Cell Physiol Biochem. 2018;47:747-58.

163. Cheng Y, Ban RW, Liu W, Wang HZ, Li SZ, Yue ZF, Zhu G, Zhuan Y, Wang CJ. MiRNA-409-3p enhances cisplatin-sensitivity of ovarian cancer cells by blocking the autophagy mediated by Fip200. Oncol Res. 2018. https ://doi.org/10.3727/096504017X15138991620238.

164. Chen G, Hu X, Zhang W, Xu N, Wang FQ, Jia J, Zhang WF, Sun ZJ, Zhao YF. Mammalian target of rapamycin regulates isoliquiritigenin-induced autophagic and apoptotic cell death in adenoid cystic carcinoma cells. Apoptosis. 2012;17:90-101.

165. Driscoll J, Anaissie EJ, Jagannathan S. Autophagy is uncoupled from ATG5-dependent apoptosis in cells resistant to proteasome inhibition. Blood. 2013;122:4448.

166. Preiss R, Tyrawa $C$, van der Merwe G. Autophagy gene overexpression in Saccharomyces cerevisiae perturbs subcellular organellar function and accumulates ROS to accelerate cell death with relevance to sparkling wine production. Appl Microbiol Biotechnol. 2018;102:8447-64.

167. Wang P, Nolan TM, Yin YH, Bassham DC. Identification of transcription factors that regulate ATG8 expression and autophagy in Arabidopsis. Autophagy. 2020;16:123-39.

168. Tai S, Sun Y, Liu N, Ding BX, Hsia E, Bhuta S, Thor RK, Damoiseaux R, Liang CZ, Huang JT. Combination of Rad001 (Everolimus) and Propachlor synergistically induces apoptosis through enhanced autophagy in prostate cancer cells. Mol Cancer Ther. 2012;11:1320-31.

169. Li B, Zhou C, Yi L, Xu LS, Xu MH. Effect and molecular mechanism of mTOR inhibitor rapamycin on temozolomide-induced autophagic death of U251 glioma cells. Oncol Lett. 2018;15:2477-84.
170. Jiang H, Sun J, Xu Q, Liu Y, Wei J, Young CYF, Yuan H, Lou H. Marchantin $M$ : a novel inhibitor of proteasome induces autophagic cell death in prostate cancer cells. Cell Death Dis. 2013:4:e761.

171. Kozako T, Mellini P, Ohsugi T, Aikawa A, Uchida YI, Honda SI, Suzuki T. Novel small molecule SIRT2 inhibitors induce cell death in leukemic cell lines. BMC Cancer. 2018;18:791.

172. Mrakovcic M, Kleinheinz J, Frohlich LF. Histone deacetylase inhibitorinduced autophagy in tumor cells: implications for p53. Int J Mol Sci. 2017;18:1883

173. Lee TG, Jeong EH, Kim SY, Kim HR, Kim CH. The combination of irreversible EGFR TKIs and SAHA induces apoptosis and autophagy-mediated cell death to overcome acquired resistance in EGFRT790M-mutated lung cancer. Int J Cancer. 2015;136:2717-29.

174. Balvers RK, Lamfers MLM, Kloezeman JJ, Kleijn A, Pont LMEB, Dirven CMF, Leenstra S. ABT-888 enhances cytotoxic effects of temozolomide independent of MGMT status in serum free cultured glioma cells. J Transl Med. 2015;13:74.

175. Lian J, Wu X, He F, Karnak D, Tang W, Meng Y, Xiang D, Ji M, Lawrence TS, $\mathrm{Xu}$ L. A natural BH3 mimetic induces autophagy in apoptosis-resistant prostate cancer via modulating BCl-2-Beclin1 interaction at endoplasmic reticulum. Cell Death Differ. 2011;18:60-71.

\section{Publisher's Note}

Springer Nature remains neutral with regard to jurisdictional claims in published maps and institutional affiliations.
Ready to submit your research? Choose BMC and benefit from:

- fast, convenient online submission

- thorough peer review by experienced researchers in your field

- rapid publication on acceptance

- support for research data, including large and complex data types

- gold Open Access which fosters wider collaboration and increased citations

- maximum visibility for your research: over $100 \mathrm{M}$ website views per year

At BMC, research is always in progress.

Learn more biomedcentral.com/submissions 